\title{
A Subpopulation of Olfactory Bulb GABAergic Interneurons Is Derived from Emx1- and Dlx5/6-Expressing Progenitors
}

\author{
Minoree Kohwi, ${ }^{1 \star}$ Magdalena A. Petryniak, ${ }^{2 \star}$ Jason E. Long, ${ }^{3}$ Marc Ekker, ${ }^{4}$ Kunihiko Obata, ${ }^{5}$ Yuchio Yanagawa, ${ }^{6}$ \\ John L. R. Rubenstein, ${ }^{3}$ and Arturo Alvarez-Buylla ${ }^{1}$ \\ ${ }^{1}$ Department of Neurosurgery and Developmental and Stem Cell Biology Program, University of California at San Francisco, San Francisco, California \\ 94143, ${ }^{2}$ Department of Pediatrics, University of California at San Francisco, San Francisco, California 94143-0748, ${ }^{3}$ Nina Ireland Laboratory of \\ Developmental Neurobiology, Department of Psychiatry, University of California at San Francisco, San Francisco, California 94158-2611, ${ }^{4}$ Department of \\ Biology, University of Ottawa, Ottawa, Ontario, Canada K1N 6N5, ${ }^{5}$ Obata Research Unit, RIKEN Brain Science Institute, Wako 351-0198, Japan, and \\ ${ }^{6}$ Department of Genetic and Behavioral Neuroscience, Gunma University Graduate School of Medicine and Solution-Oriented Research for Science and \\ Technology, Japan Science and Technology Agency, Maebashi 371-8511, Japan
}

The subventricular zone (SVZ) of the postnatal brain continuously generates olfactory bulb (OB) interneurons. We show that calretinin ${ }^{+}$, calbindin ${ }^{+}$, and dopaminergic $\left(\mathrm{TH}^{+}\right)$periglomerular $\mathrm{OB}$ interneurons correspond to distinct subtypes of GABAergic cells; all were produced in the postnatal mouse brain, but they matured and were eliminated at different rates. The embryonic lateral ganglionic eminence (LGE) is thought to be the site of origin of postnatal SVZ neural progenitors. Consistently, grafts of the embryonic LGE into the adult brain SVZ generated many OB interneurons, including $\mathrm{TH}^{+}$and calbindin ${ }^{+}$periglomerular interneurons. However, calretinin ${ }^{+}$ cells were not produced from these LGE grafts. Surprisingly, pallial and septal embryonic progenitors transplanted into the adult brain SVZ also resulted in the generation of $\mathrm{OB}$ interneurons, including calretinin ${ }^{+}$cells. A subset of $\mathrm{Dlx} 2^{+} \mathrm{OB}$ interneurons was derived from cells expressing $E m x 1$, a transcription factor largely restricted to the pallium during development. Emx 1 lineage-derived cells contributed a substantial portion of GABAergic cells in the $\mathrm{OB}$, including calretinin ${ }^{+}$interneurons. This is in contrast to cortex, in which Emx1 lineage-derived cells do not differentiate into GABAergic neurons. Our results suggest that some OB interneurons are derived from progenitors outside the LGE and that precursors expressing what has classically been considered a pallial transcription factor generate GABAergic interneurons.

Key words: pallial; Dlx2; Emx1; SVZ; GABAergic neuron; neurogenesis; olfactory bulb

\section{Introduction}

The adult rodent brain harbors two germinal regions that exhibit neurogenesis throughout life, the dentate gyrus of the hippocampus (Palmer et al., 1999; Kempermann et al., 2004) (for review, see Aimone et al., 2006) and the subventricular zone (SVZ) of the lateral ventricles (for review, see Temple, 2001) (Alvarez-Buylla and Garcia-Verdugo, 2002; Kohwi et al., 2006). Neuroblasts born in the SVZ migrate a long distance to the olfactory bulb $(\mathrm{OB})$,

Received Jan. 19, 2007; revised May 17, 2007; accepted May 19, 2007.

This work was supported by research grants to J.L.R.R. from Nina Ireland, the Larry L. Hillblom Foundation, and the National Institute of Mental Health (R01 MH49428-01 and K05 MH065670); and to A.A.B. from the National Institute of Neurological Disorders and Stroke (NS 028478) and the National Institute of Child Health and Human Development (NICHD; HD 32116) and John and Frances Bowes. M.A.P. was supported by a training research grant from the NICHD (HD-071628H). M.K. was supported by a National Research Service Award training grant (NRSA1F31DC008057). We thank Kevin Jones for the Emx1-cre mice and David Eisenstat for the Dlx2 antibody. We thank Gregory Potter for critical reading and preparation of this manuscript, interpretation of results, and assistance with experiments. We also thank Rui Galvão for productive discussion regarding design of experiments and data analyses. ${ }^{*}$ M.K. and M.A.P. contributed equally to this work.

Correspondence should be addressed to either of the following: John L. R. Rubenstein, Nina Ireland Laboratory of Developmental Neurobiology, Department of Psychiatry, University of California at San Francisco, San Francisco, CA 94158-2611, E-mail: john.rubenstein@ucsf.edu; or Arturo Alvarez-Buylla, Department of Neurosurgery and Developmental and Stem Cell Biology Program, University of California at San Francisco, San Francisco, CA 94143, E-mail: abuylla@stemcell.ucsf.edu.

DOI:10.1523/JNEUROSCI.0254-07.2007

Copyright $\odot 2007$ Society for Neuroscience $\quad 0270-6474 / 07 / 276878-14 \$ 15.00 / 0$ where they become periglomerular and granular interneurons (Alvarez-Buylla and Garcia-Verdugo, 2002). These interneurons modulate the activity of mitral and tufted cells, the projection neurons that relay sensory input from the olfactory epithelia directly to the cortex. The periglomerular and granule cells in turn are subdivided into several subtypes, differing in their functions within the OB circuit (Shepherd, 1972). The best characterized are three major classes of periglomerular cells (PGCs), which include the dopaminergic interneurons [tyrosine hydroxylase positive $\left(\mathrm{TH}^{+}\right)$] and calbindin ${ }^{+}$and calretinin ${ }^{+}$cells (Kosaka et al., 1998).

OB interneurons begin to be generated before birth, reaching a peak early postnatally (Hinds, 1968). Little is known about their embryonic origins and how the genetic profiles of SVZ progenitors differ from neural progenitors that cease neurogenesis at birth. Numerous studies suggest that the lateral ganglionic eminence (LGE), and specifically its dorsal aspect (dLGE), of the embryonic forebrain is the origin of the adult SVZ (Wichterle et al., 1999; Marin and Rubenstein, 2001; Toresson and Campbell, 2001; Stenman et al., 2003; Yun et al., 2003; Waclaw et al., 2006). Heterochronic/homotopic grafting of embryonic LGE progenitors into the adult brain generates OB interneurons (Wichterle et al., 1999), whereas mice genetically lacking transcription factors 

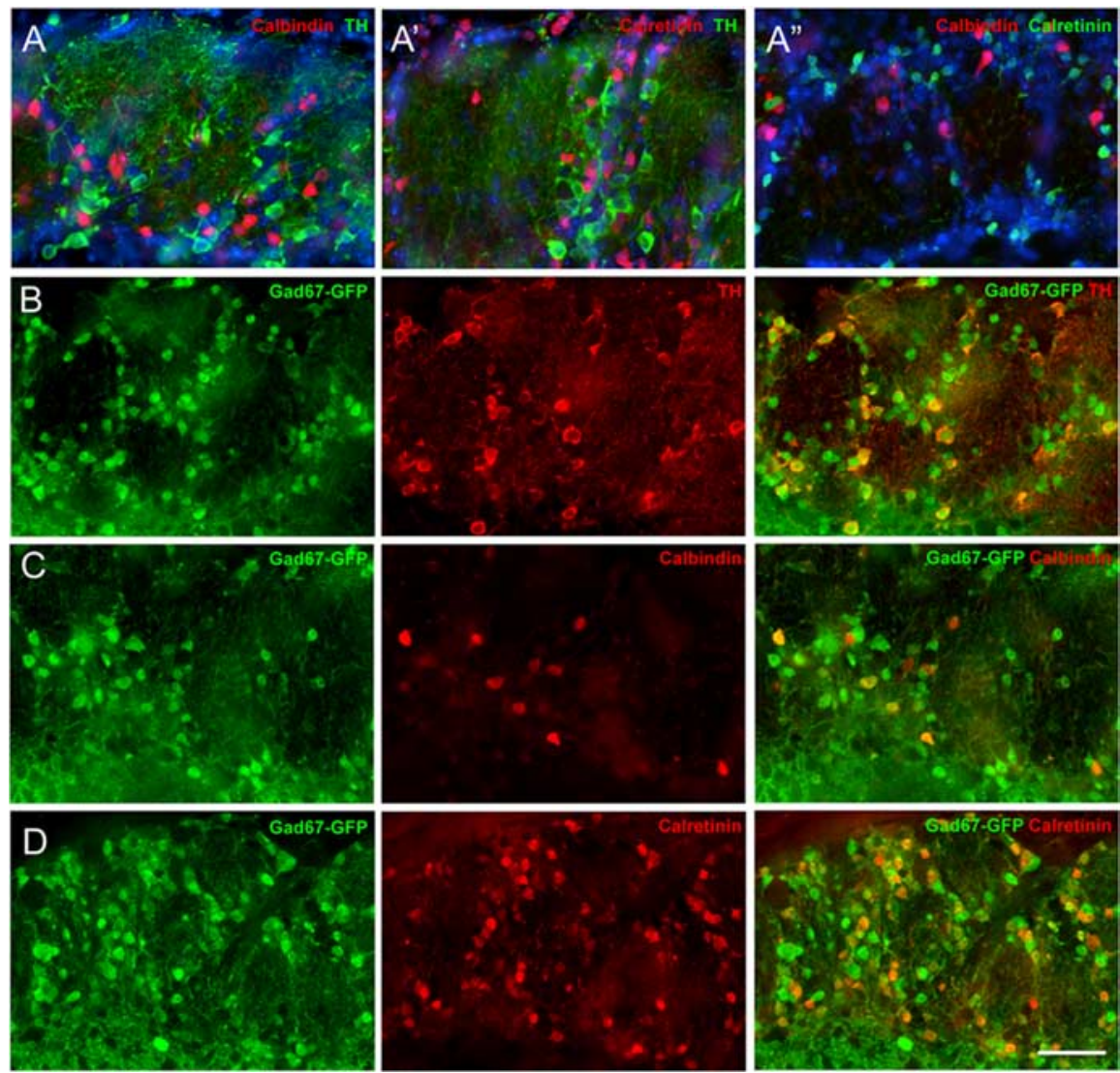

Figure 1. $\mathrm{TH}^{+} /$calbindin ${ }^{+} /$calretinin ${ }^{+}$cells are distinct subtypes of GABAergic cells in the $O B$. $A-A^{\prime \prime}$, TH, calbindin, and calretinin expression does not overlap. $\boldsymbol{B}-\boldsymbol{D}$, TH, calbindin, and calretinin expression overlaps with EGFP in Gad67-EGFP $(\Delta$ neo $)$ mouse OB. Scale bar, $50 \mu \mathrm{m}$.

expressed in the dLGE show a loss of OB interneurons (Anderson et al., 1997b; Bulfone et al., 1998; Corbin et al., 2000; Toresson et al., 2000; Toresson and Campbell, 2001; Yun et al., 2001, 2003). The transcription factor Pax6, expressed in the dLGE and pallium, is required for the production of the dopaminergic periglomerular cells (Hack et al., 2005; Kohwi et al., 2005).

Recently, Waclaw et al. (2006) reported that loss of the transcription factor Sp8 in the subpallium, using Dlx5/6-cre, results in a $50 \%$ reduction in calretinin ${ }^{+}$PGCsbut a much smaller reduction in dopaminergic cells. Thus, multiple transcriptional programs function to generate the full complement of OB interneuron subtypes. However, $\mathrm{Sp} 8$ is expressed in regions outside of the LGE, including the pallium and septum, and previous studies have not addressed whether all OB interneuron subtypes originate from the LGE.

Here, we show that all major subtypes of periglomerular $\mathrm{OB}$ interneurons are generated from the perinatal period through adulthood, but these cells mature and are replaced at different rates. Grafts of the embryonic LGE, including the dorsal LGE, into the adult brain SVZ resulted in the generation of many OB interneurons but not calretinin ${ }^{+}$periglomerular or granule cells. Cre-mediated lineage tracing of progenitors expressing Emx1 generated $\mathrm{OB}$ interneurons, including calretinin ${ }^{+}$cells. Calreti$\mathrm{nin}^{+}$cells could also be lineage traced from Dlx5/6i-cre mice, suggesting that a subpopulation of PGCs is derived from progenitors that at some point in their development express transcription factors typically associated with both the pallium and subpallium. Consistently, transplantation of both embryonic pallial and septal progenitors into the adult brain SVZ generated calreti- $\operatorname{nin}^{+}$interneurons. These results show that some OB interneurons can originate from progenitors outside the LGE and that precursors expressing the pallial transcription factor Emxl generate GABAergic interneurons.

\section{Materials and Methods}

Animals. Mice were maintained in standard conditions with food and water ad libitum. The Committees on Animal Health and Care at University of California at San Francisco (UCSF) approved all experimental procedures. Adult male CD1 mice were purchased from Charles River Laboratories (Wilmington, MA). Transgenic mice expressing enhanced green fluorescent protein (EGFP) and Z/EG mice were commercially obtained from The Jackson Laboratory (Bar Harbor, ME). Emx1-cre mice were a gift from Kevin Jones (Gorski et al., 2002). Gad67-EGFP ( $\Delta$ neo) mice were provided by Kunihiko Obata and Yuchio Yanagawa (Gunma University, Maebashi, Japan). The Dlx5/6i-cre mice were provided by Marc Ekker (University of Ottawa, Ottawa, Ontario, Canada). All lines were in a mixed genetic background of C57BL/6/6J/CD1. Genotyping was performed by PCR as described previously: Gad67-EGFP ( $\Delta$ neo) (Tamamaki et al., 2003); Emx1-cre (Gorski et al., 2002); Dlx5/6i-cre (Monory et al., 2006); Z/EG (Novak et al., 2000); $\beta$-actin-EGFP (Hadjantonakis et al., 1998). Mouse colonies were maintained at the University of California, San Francisco, in accordance with National Institutes of Health and UCSF guidelines.

Histology. Pregnant females were anesthetized with isofluorene, embryonic day 15.5 (E15.5) pups were extracted from the uterus, and the brains were dissected and fixed with $4 \%$ paraformaldehyde (PFA) in PBS (0.1 M), pH 7.4. Mouse pups [postnatal day $0(\mathrm{P} 0)]$ were deeply anesthetized on ice. The brains were removed and fixed overnight in 4\% PFA and then cryoprotected by immersion in 30\% sucrose. E15.5 and P0 brain sections were cut at a thickness of $10 \mu \mathrm{m}$ on a cryostat and mounted on Fisher (Hampton, NH) Superfrost/Plus slides. Adult mice (2-3 months of age) were deeply anesthetized with Avertin $(0.2 \mathrm{ml} / 10 \mathrm{~g}$ of body weight; Sigma-Aldrich, St. Louis, MO) before intracardiac perfusion with $4 \%$ PFA in PBS and postfixed overnight in the same fixative. Sections were cut on a vibratome and stained as $50 \mu \mathrm{m}$ floating sections.

Bromodeoxyuridine injections. Adult CD-1 animals (60 d of age) received a single intraperitoneal injection with the DNA synthesis marker bromodeoxyuridine (BrdU; $50 \mathrm{mg} / \mathrm{kg}$ ) and were killed at different survival times for analyses.

Transplantation. $\beta$-Actin-EGFP mice were maintained on a CD-1 background. dLGE, pallium, or septum from E16.5, timed-pregnant $\beta$-actin-EGFP embryos were harvested and then transplanted into the SVZ of adult CD-1 mice (P90) at the following stereotaxic coordinates: anterior-posterior (AP) $0.5 \mathrm{~mm}$, medial-lateral (ML) $1.1 \mathrm{~mm}$, and dorsal-ventral (DV) $1.7 \mathrm{~mm}$; and AP $1 \mathrm{~mm}$, ML $1 \mathrm{~mm}$, and DV $2.3 \mathrm{~mm}$. dLGE progenitors were obtained by dissecting between the sulcus separating the pallium from the subpallium and the middle of the LGE as indicated in the schematic of Figure 3. These dissections may include a small contamination of ventral pallial progenitors but do not contain medial ganglionic eminence (MGE) progenitors or dorsal pallium. Pallial progenitors were obtained from the pallium medial from the pallialsubpallial sulcus (Fig. 10, schematic). Similarly, septal progenitors were obtained excluding pallium or lateral wall tissue as indicated in the schematic of Figure 11. Brains from grafted animals were removed after in- 
tracardiac perfusion with $4 \%$ PFA and were cut into $50 \mu \mathrm{m}$ sections on a vibratome as described above.

Immunohistochemistry. We used the following primary antibodies: chicken anti-GFP, 1:500 (Aves Labs, Tigard, OR); rabbit anti-TH, 1:500 (Pel-Freeze, Rogers, AR); goat anticalretinin, 1:500 (Millipore, Billerica, MA); rabbit anti-calbindin, 1:4000 (Swant, Bellinzona, Switzerland); rabbit anti-DLX2, 1:100 (kind gift from Dr. David Eisenstat, Winnipeg Institute of Cell Biology, Winnipeg, Manitoba, Canada); rat anti-BrdU, 1:10 (AbCam, Cambridge, MA); rabbit anti-Ki67, 1:1000 (Novocastra, UK); rabbit anti-GABA, 1:2000 (SigmaAldrich); guinea pig anti-vesicular glutamate transporter 1 and 2 (vGlut1/2), 1:5000 (Millipore); mouse anti-Reelin, 1:500 (Millipore). Secondary antibodies all were labeled with Alexa Fluors and were used at 1:500 (Invitrogen, Eugene, OR): goat anti-chicken 488, donkey anti-rabbit 594/488, donkey anti-rat 594, and donkey anti-mouse 594/488. Sections were blocked for $1 \mathrm{~h}$ at room temperature with $5 \%$ serum, $2 \%$ bovine serum albumin, and $0.1 \%$ Triton X-100. Primary antibodies were incubated at $4^{\circ} \mathrm{C}$ overnight, and secondary antibodies were incubated for $1 \mathrm{~h}$ at room temperature. Sections were counterstained with DAPI $\left(4^{\prime}, 6^{\prime}\right.$ diamidino-2-phenylindole) and analyzed using the Olympus (Melville, NY) AX700 light microscope. Confocal images at $63 \times$ magnification were taken using Leica (Bannockburn, IL) SP2. For quantifying EGFP and TH/calretinin/calbindin double labeling, each $\mathrm{EGFP}^{+}$cell was imaged at $40 \times$. For BrdU labeling, vibratome sections were treated with $2 \mathrm{~N} \mathrm{HCl}$ for $30 \mathrm{~min}$ at $37^{\circ} \mathrm{C}$ and $0.1 \mathrm{M}$ boric acid for $10 \mathrm{~min}$ at room temperature before antibody incubation.

\section{Results}

$\mathrm{TH}^{+}$, calbindin ${ }^{+}$, and calretinin ${ }^{+}$cells are distinct classes of GABAergic

$\mathrm{OB}$ interneurons

The mouse OB contains three subtypes of nonoverlapping populations of PGCs (Fig. $1 A-A^{\prime \prime}$ ), characterized by expression of TH, calbindin, and calretinin. To determine which of these OB interneuron subtypes are GABAergic, we studied TH, calbindin, and calretinin expression in Gad67-GFP ( $\Delta$ neo) mice that express EGFP under the control of the endogenous Gad67 promoter (Tamamaki et al., 2003). We found that $\mathrm{TH}^{+}$, calbindin ${ }^{+}$, and calretinin ${ }^{+}$cells were all GFP labeled, indicating that in mouse these three subtypes of periglomerular interneurons are GABAergic (Fig. $1 B-$ $D)$. Calretinin was also expressed in a subpopulation of superficial GABAergic granule cells (data not shown).

$\mathrm{TH}^{+}$, calbindin ${ }^{+}$, and calretinin ${ }^{+} \mathrm{OB}$ interneurons are replaced at different rates in the adult brain

We next analyzed the time course of recruitment of new $\mathrm{TH}^{+}$, calbindin $^{+}$, and calretinin ${ }^{+}$interneurons in adult mice. Sixtyday-old mice received a single injection of BrdU. The proportion of $\mathrm{BrdU}^{+}$cells that expressed $\mathrm{TH}$, calbindin, or calretinin was

C $\mathrm{P} 0, \mathrm{P} 100$, and P300 animals.
$\%$ BrdU+cells that express subtype-specific OB interneruon markers

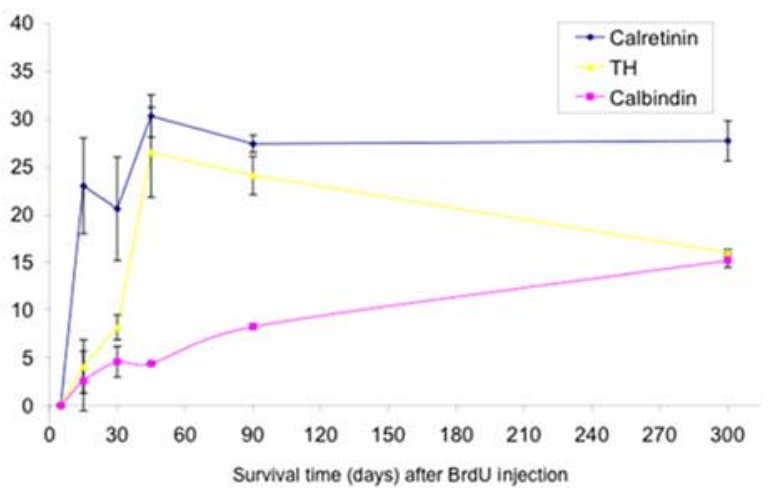

BrdU-labeled Calretinin/TH/Calbindin cells per glomerulus

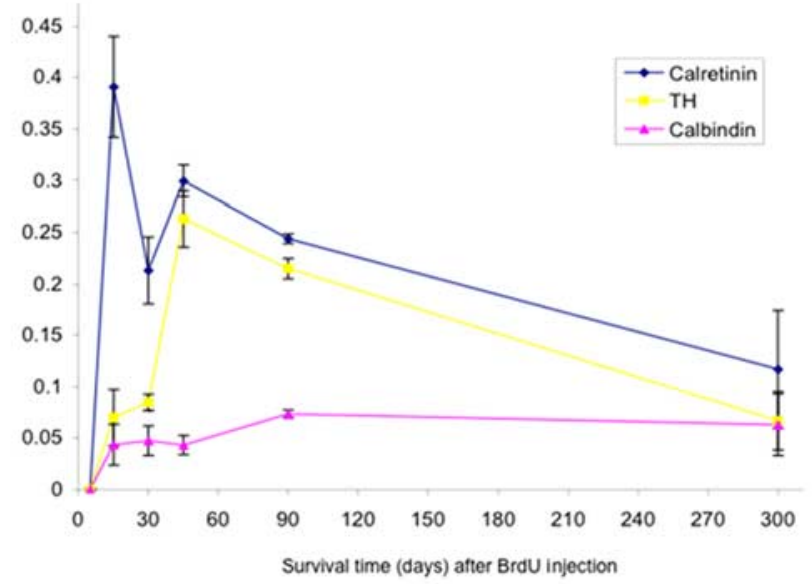

Figure 2. TH/calbindin/calretinin OB interneurons are replaced at different rates during adult SVZ neurogenesis. $\boldsymbol{A}$, Time course of maturation of $\mathrm{TH}$, calbindin, and calretinin cells. BrdU was injected once, and animals were killed after varying times. The graph illustrates the percentage of BrdU ${ }^{+}$cells that coexpressed cell type-specific markers at different survival time points. Error bars represent SEM (counted from 3 animals per time point). $\boldsymbol{B}$, The graph in $\boldsymbol{A}$ represented as absolute numbers of cells per glomerulus at each survival time point. C, Pie charts showing the ratio of $\mathrm{TH}$ :calbindin (CaIB):calretinin (CaIR) cells in glomerular layer of OB in

analyzed at different survival times. Fifteen days post-BrdU injection, only a few $\mathrm{BrdU}^{+}$cells expressed either TH or calbindin $(4.1 \pm 2.8$ and $2.6 \pm 1.2 \%$, respectively), whereas $23.0 \pm 5.0 \%$ already expressed calretinin (Fig. 2 A). Forty-five days post-BrdU injection, the fraction of $\mathrm{BrdU}^{+}$PGCs that express either calretinin or $\mathrm{TH}$ reached a maximum (at $30.0 \pm 2.2$ and $26.5 \pm 4.7 \%$, respectively), after which the proportion of $\mathrm{BrdU}^{+}$cells that express these markers decreased. By multiplying the percentage of $\mathrm{BrdU}^{+}$cells that expressed each cell type-specific marker by the mean number of $\mathrm{BrdU}^{+}$cells per glomerulus, we calculated the total number of new $\mathrm{TH}^{+}$, calbindin ${ }^{+}$, and calretinin ${ }^{+}$cells at each survival time point after BrdU injection (Fig. 2 B). Because a 


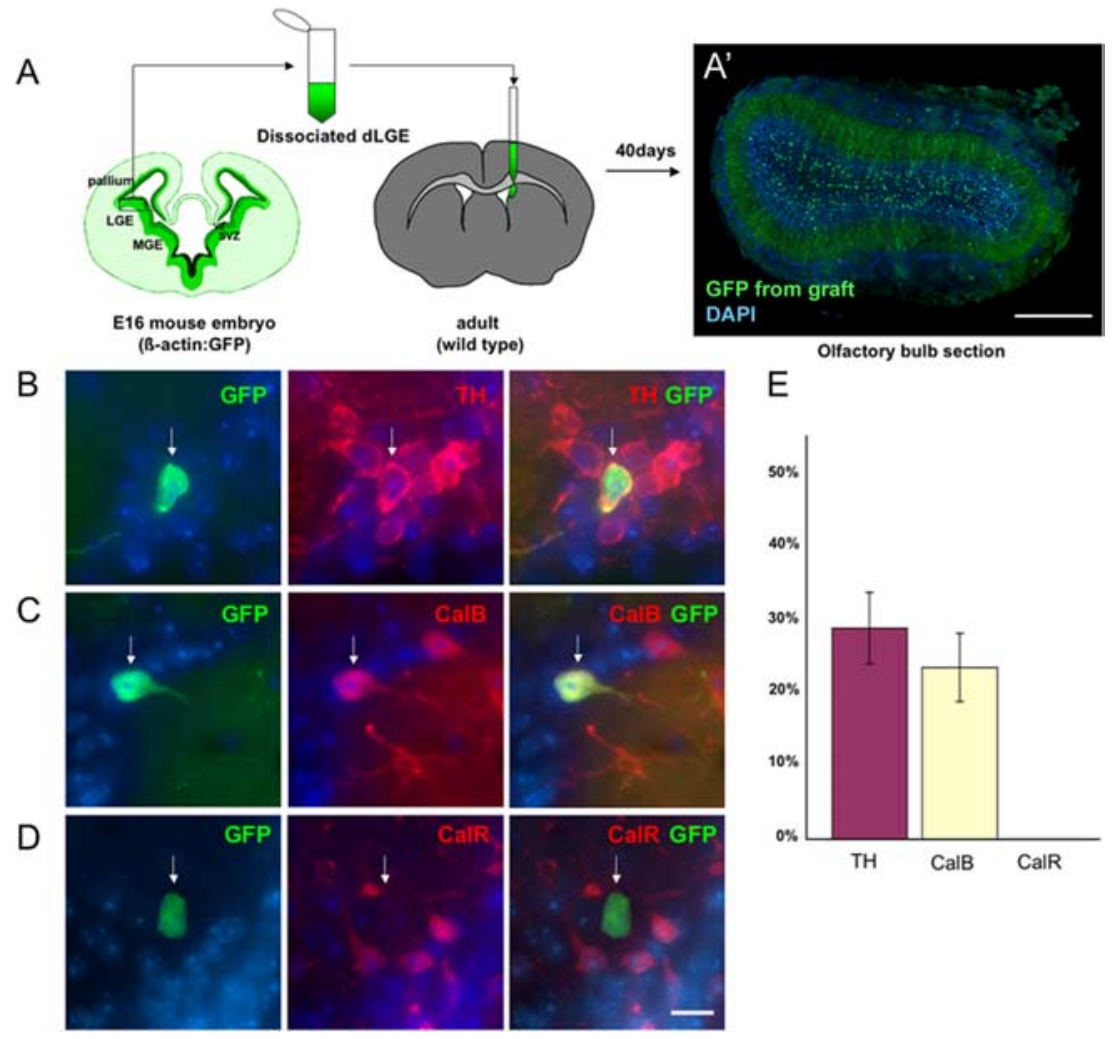

Figure 3. Calretinin ${ }^{+}$cells are not generated from LGE progenitors grafted to adult SVZ. $\boldsymbol{A}$, Schematic of transplantation experiment. $\boldsymbol{A}^{\prime}$, Overview of $O B$ section showing that graft-derived cells migrate to interneuron layers. $\boldsymbol{B}-\boldsymbol{D}$, Examples of $L G E$ graft-derived cells that coexpress TH and calbindin (CalB) but not calretinin (CaIR). $\boldsymbol{E}$, Quantification of LGE graft experiment. $y$-Axis shows percentage of graft-derived cells coexpressing $\mathrm{TH}$, calbindin, or calretinin. Error bars represent SEM. Arrows show corresponding locations in the three panels. Scale bars: $\boldsymbol{A}^{\prime}, 0.5 \mathrm{~mm} ; \boldsymbol{B}-\boldsymbol{D}, 10 \mu \mathrm{m}$.

single pulse of BrdU labels one cohort of newly generated interneurons, the decrease in the proportion of $\mathrm{BrdU}^{+}$cells that express $\mathrm{TH}$ and calretinin most likely reflects the loss of these cells. In contrast, the fraction of $\mathrm{BrdU}^{+}$cells that expresses calbindin increased from day 15 to day 90 , after which it appeared to plateau through day 300. Therefore, all three interneuron subtypes are produced in the adult brain, but they appear to mature and be eliminated at different rates.

As indicated above, $45 \mathrm{~d}$ after BrdU injection the percentage of $\mathrm{BrdU}^{+}$cells that expresses $\mathrm{TH}$ and calretinin peaked at 27 and $30 \%$, respectively. In contrast, the proportion of $\mathrm{BrdU}^{+}$cells that expresses calbindin was much lower $(4.4 \pm 0.9 \%)$, and this fraction continued to increase with time (Fig. $2 A$ ). The ratio of $\mathrm{TH}^{+}$: calbindin ${ }^{+}$:calretinin ${ }^{+}$was $\sim 1: 1: 2$ (Fig. $2 C$ ) at all ages studied (P0, P90, and P300). This suggests that $\mathrm{TH}^{+}$cells must have a higher turnover rate compared with calretinin ${ }^{+}$cells, and calbindin ${ }^{+}$cells must have a lower rate. The increase in the proportion of $\mathrm{BrdU}^{+}$cells that express calbindin after the BrdU injection suggests that this cell type has a long lifespan. Consistently, $\mathrm{BrdU}^{+}$calbindin ${ }^{+}$cells persisted for long periods up to at least 10 months after the BrdU injection (Fig. $2 B$ ). In contrast, the number of calretinin and $\mathrm{TH}^{+}$PGCs generated in the adult steadily decreased after $45 \mathrm{~d}$, and the number of $\mathrm{TH}^{+}$cells decreased faster than calretinin ${ }^{+}$cells (Fig. 2 B). Together, the data show that all three main subtypes of PGCs are generated in the adult brain, but the rate at which these cells mature and are replaced is distinct for each cell type.
LGE progenitors transplanted to the adult $S V Z$ give rise to $O B$ interneurons but not the calretinin ${ }^{+}$subtype

To determine the subtypes of OB interneurons that are derived from the LGE, we used heterochronic transplantations. The dLGE was microdissected from E16 transgenic mice expressing EGFP under the $\beta$-actin promoter (Okabe et al., 1997). dLGE cells were dissociated and grafted into the dorsal SVZ of 3-month-old wildtype mice (Fig. 3A). Grafted cells migrated into the $\mathrm{OB}$ and differentiated into different types of interneurons (Kohwi et al., 2005). Forty days after the transplantation, the phenotype of EGFP-labeled OB interneurons was determined. Of all $\mathrm{EGFP}^{+}$cells around glomeruli, $29 \pm 4.9 \%$ ( 194 cells counted; $n=3$ mice) expressed $\mathrm{TH}$, and $24 \pm 4.7 \%$ expressed calbindin (of 381 cells counted; $n=3$ mice). There were also numerous $\mathrm{EGFP}^{+}$neurons in the granule cell layer (data not shown) (Kohwi et al., 2005). Strikingly, however, no calretinin ${ }^{+}$periglomerular or granule neurons were observed in these LGEgrafted animals (Fig. 3). A similar observation has recently been reported (De Marchis et al., 2007).

Because progenitors grafted into the adult SVZ continually generate neuroblasts, at any given point in time when the $\mathrm{OB}$ is examined, there will be $\mathrm{EGFP}^{+}$cells at different stages of maturation; these include neuroblasts that have just arrived in the $\mathrm{OB}$ as well as neurons that have begun but not completed their differentiation. The $\sim 50 \%$ of $\mathrm{EGFP}^{+}$cells that did not stain for $\mathrm{TH}$, calbindin, or calretinin may include neurons that have not fully differentiated, a different class of interneuron, or cells that differentiated into glial cells. Our data show that E16 LGE progenitors are capable within the adult SVZ environment of generating $\mathrm{OB}$ interneurons that differentiate into $\mathrm{TH}^{+}$or calbindin ${ }^{+}$cells, but not calretinin ${ }^{+}$cells.

OB interneuron production begins as early as E14 (Wichterle et al., 2001; Tucker et al., 2006), and by P0, many calreti$\operatorname{nin}^{+}$PGCs are already present (Figs. $2 C, 4 B$ ). To test the possibility that calretinin ${ }^{+}$PGCs were generated from an earlier age, we grafted LGE from E14 embryos to adult SVZ. No calretinin $^{+}$PGCs were generated from these grafts either, although both $\mathrm{TH}^{+}$and calbindin ${ }^{+}$cells were produced (data not shown), again suggesting that the LGE does not contribute to calretinin ${ }^{+} \mathrm{OB}$ interneurons. It is possible that calretinin ${ }^{+}$ cells found in the neonatal OB may be generated in the LGE a day or two before birth (i.e., E17-E18). This is, however, unlikely given that at birth there are already many calretinin ${ }^{+}$ interneurons in the OB. An alternative possibility is that embryonic progenitors outside the dLGE produce this interneuron subtype.

Recent studies indicate that the caudal ganglionic eminence (CGE) produces neuroblasts that migrate to the cortex and become calretinin ${ }^{+}$interneurons (Lopez-Bendito et al., 2004; Xu et al., 2004). We therefore tested whether the CGE may also contribute to this population of interneurons in the 

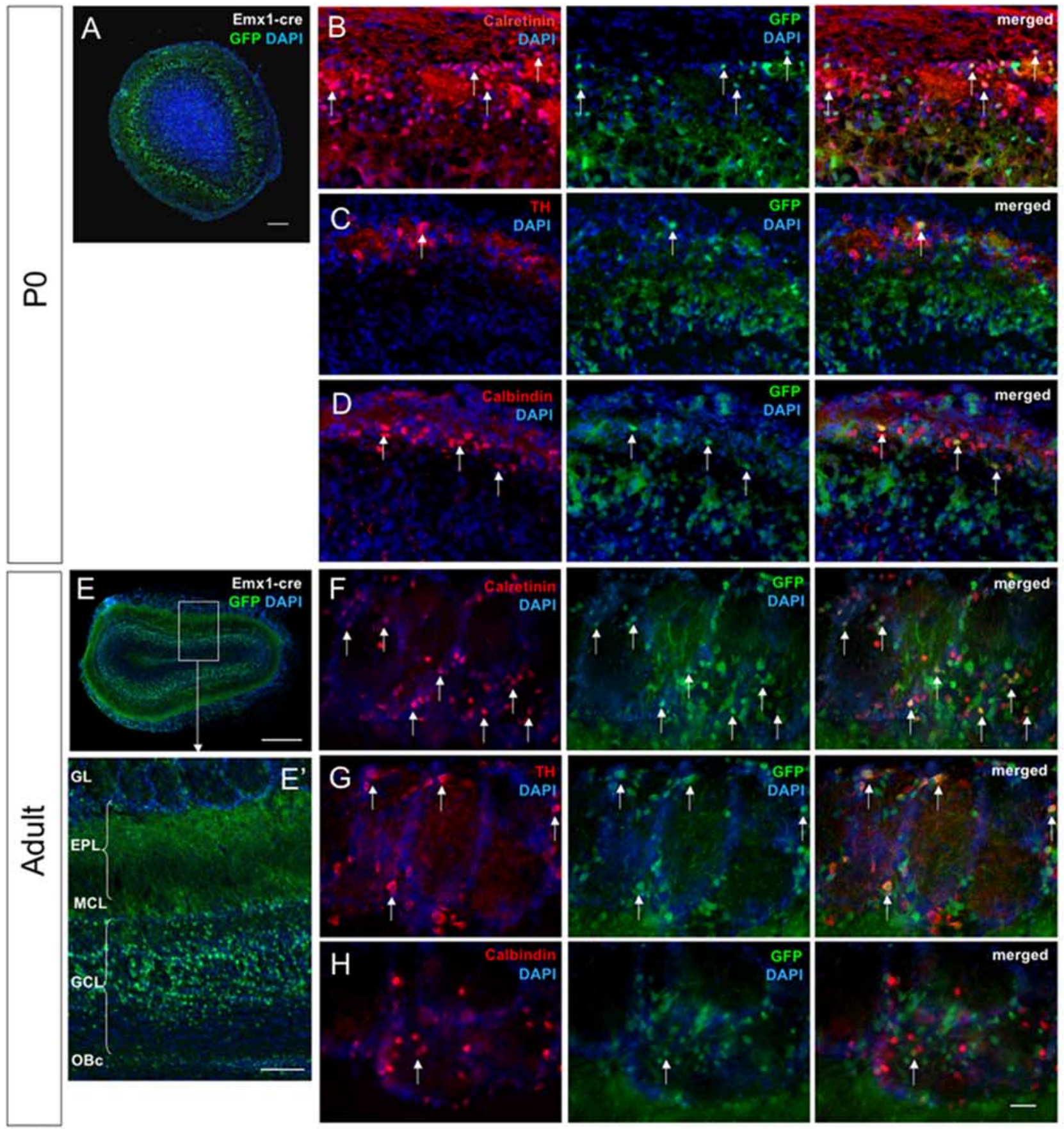

\section{$\underline{P 0}$}

\section{J Adult}
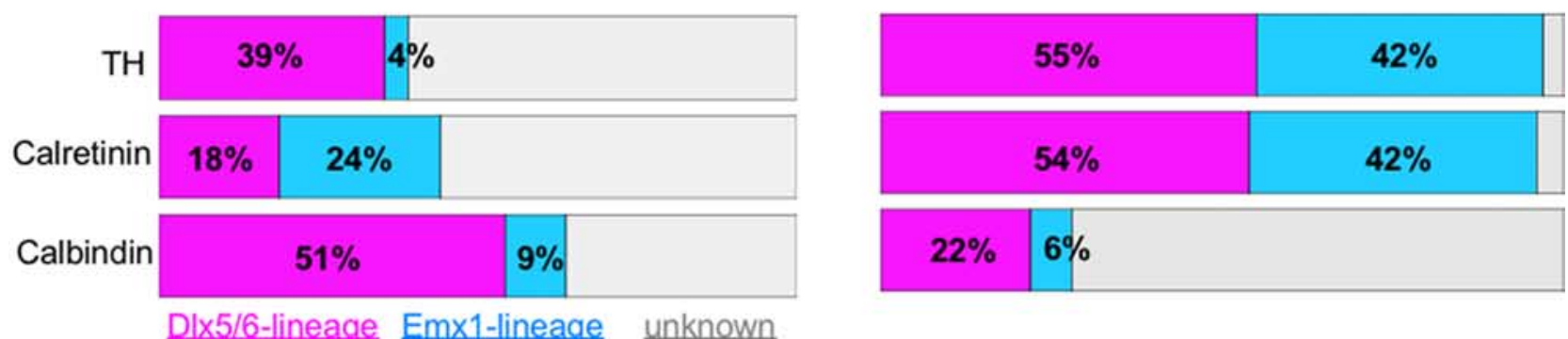

Figure 4. Emx1 lineage gives rise to $\mathrm{TH}^{+} /$calbindin ${ }^{+} /$calretinin ${ }^{+} \mathrm{OB}$ interneurons. $\boldsymbol{A}$, EGFP expression in OB from Emx1 lineage at P0. $\boldsymbol{B}-\boldsymbol{D}$, Examples of EGFP ${ }^{+}$cells that coexpress TH, calbindin, or calretinin. $\boldsymbol{E}$, EGFP expression in OB from Emx1 lineage in adult. $\boldsymbol{E}^{\prime}$, Higher magnification of OB showing that EGFP expression in granule cell layer is predominantly superficial. $\boldsymbol{F}-\boldsymbol{H}$, Examples of EGFP ${ }^{+}$cells in adult $\mathrm{OB}$ that coexpress TH, calbindin, or calretinin. I-J, Quantification summary of Emx1-cre and Dlx5/6i-cre lineages at $\mathrm{P} 0$ and adult. Arrows point to double-labeled cells. GL, Glomerular layer; EPL, external plexiform layer; $\mathrm{MCL}$, mitral cell layer; $\mathrm{GCL}$, granule cell layer; $\mathrm{OBC}$, olfactory bulb core. Scale bars: $\boldsymbol{A}, \boldsymbol{E}^{\prime}, 100 \mu \mathrm{m} ; \boldsymbol{B}-\boldsymbol{D}, \boldsymbol{F}-\boldsymbol{H}, 30 \mu \mathrm{m} ; \boldsymbol{E}, 0.5 \mathrm{~mm}$. 


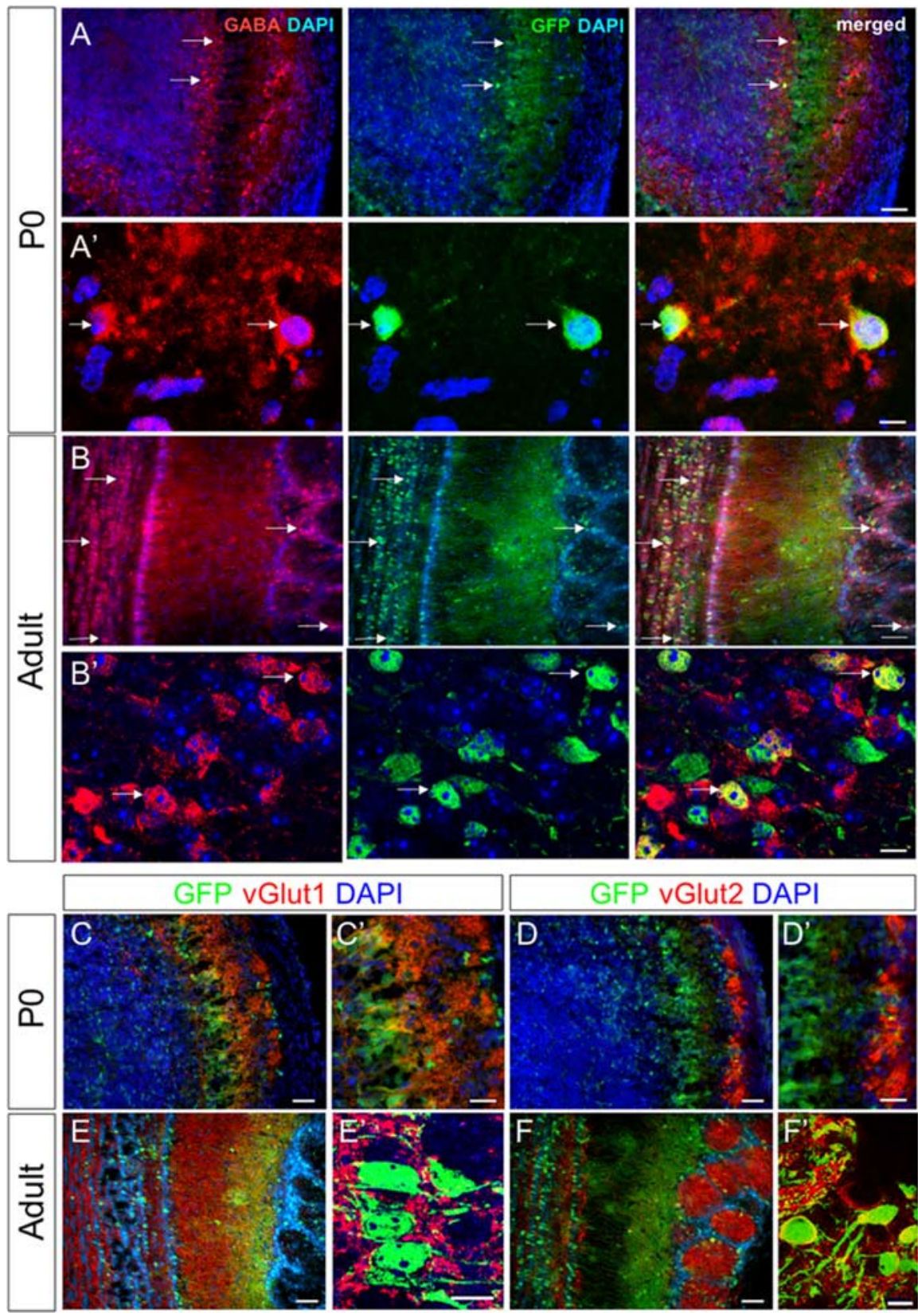

Figure 5. Emx 1 lineage cells give rise to GABAergic cells in $\mathrm{OB} . A, \mathrm{PO} O \mathrm{OB}$ section shows that $\mathrm{EGFP}{ }^{+} \mathrm{Emx} 1$ lineage-derived cells express GABA. $\boldsymbol{A}^{\prime}$, Higher-magnification confocal image of EGFP ${ }^{+}$cells that express GABA in glomerular layer. $\boldsymbol{B}$, Most EGFP ${ }^{+}$ cells in the adult $\mathrm{OB}$ coexpress GABA. $\boldsymbol{B}^{\prime}$, Higher-magnification confocal image of adult EGFP ${ }^{+}$cells that express GABA. $\boldsymbol{C}$, Many $\mathrm{EGFP}^{+}$cells in the mitral cell layer at $\mathrm{P} 0$ are vGlut ${ }^{+}{ }^{+}$, but EGFP ${ }^{+}$cells in the granule cell layer do not express vGlut1. $C^{\prime}$, Higher magnification of $\boldsymbol{C}$. $\boldsymbol{D}$, Few EGFP ${ }^{+}$cells in the glomerular layer at $\mathrm{PO}$ are vGlut2 ${ }^{+}$. $\boldsymbol{D}^{\prime}$, Higher magnification of $\boldsymbol{D}$. E, EGFP ${ }^{+}$cells in granule cell layer in the adult do not express vGlut1. $\boldsymbol{E}^{\prime}$, Confocal image of EGFP and vGlut1 in the granule cell layer. $\boldsymbol{F}$, Some EGFP ${ }^{+}$cells in the glomerular layer in the adult express vGlut2. $\boldsymbol{F}^{\prime}$, Confocal image of EGFP and vGlut2 in the glomerular layer. Scale bars: $\boldsymbol{A}-\boldsymbol{F}, 50 \mu \mathrm{m} ; \boldsymbol{A}^{\prime}, \boldsymbol{B}^{\prime \prime}, \boldsymbol{E}^{\prime}, \boldsymbol{F}^{\prime}, 10 \mu \mathrm{m} ; \boldsymbol{C}^{\prime}, \boldsymbol{D}^{\prime \prime}, 30 \mu \mathrm{m}$.

OB. However, in contrast to the LGE grafts, E14 CGE cells grafted into the adult SVZ $(n=3$ mice) (supplemental Fig. $1 A-C$, available at www.jneurosci. org as supplemental material) did not generate cells that migrated into the OB. These results suggest that the $\mathrm{CGE}$ is not a source of calretinin ${ }^{+} \mathrm{OB}$ interneurons.

\section{The Emx1 lineage contributes to multiple OB interneuron subtypes}

Given our results that no calretinin ${ }^{+}$cells were generated from the LGE or CGE grafts, we hypothesized that other progenitor domains may generate this $\mathrm{OB}$ interneuron subtype. A previous study used the Cre recombinase method to follow the fate of cells expressing Emxl (Gorski et al., 2002), a transcription factor expressed predominantly in pallial progenitors and their derivatives (Fernandez et al., 1998, Puelles et al., 2000; Chan et al., 2001). In addition to extensive Emxl-cre recombination in cells that differentiate into glutamatergic neurons in the cortex and $\mathrm{OB}$, Gorski et al. (2002) also reported recombination in a few radially aligned clones in the dorsal LGE of the early embryo as well as cells located in the $\mathrm{OB}$ interneuron layers.

We used the Emx1-cre mouse to determine the types of neurons formed in the $\mathrm{OB}$ granule and glomerular layers. We crossed the Emx1-cre mouse line to a transgenic reporter line, Z/EG (Novak et al., 2000), that permanently expresses EGFP in cells that had expressed Cre at some point during their development (Emx1-cre:ZEG). In agreement with Gorski et al. (2002), in the OB we found EGFP-labeled cells in the granular and glomerular layers of neonatal and adult mice (Fig. $4 A, E$ ). Interestingly, within the granule cell layer of the adult $\mathrm{OB}$, EGFP-expressing cells were predominantly in the superficial layers (Fig $\left.4 E, E^{\prime}\right)$. Within the glomerular layer, $24 \pm 0.01 \%$ of calretinin ${ }^{+}$cells were EGFP $^{+}$(Fig. $\left.4 B, I\right)$ at P0. A smaller fraction of the $\mathrm{TH}^{+}(4 \pm 0.02 \%)$ and calbi$\operatorname{ndin}^{+}(9 \pm 0.02 \%)$ interneurons were also $\mathrm{EGFP}^{+}$(Fig. 4C,D) at this age. Analysis of adult Emx1-cre:ZEG mice showed that the Emx1 lineage contributed $42 \pm 2.0 \%$ of calretinin ${ }^{+}, 42 \pm$ $0.8 \%$ of $\mathrm{TH}^{+}$, and $6 \pm 0.8 \%$ of calbindin ${ }^{+}$PGCs ( $n=3$ mice) (Fig. $4 F-$ $H, J)$. Interestingly, a large proportion of calretinin ${ }^{+}$cells in the granule cell layer were also $\mathrm{EGFP}^{+}(45.4 \% ; n=4$ adult mice). The above results indicate that the Emx1 lineage contributes to multiple OB interneurons, including the calreti$\operatorname{nin}^{+}$subpopulation.

Because within the neocortex the Emx 1 lineage gives rise to glutamatergic,

and not GABAergic, neurons (Gorski et al., 2002), we wanted to confirm that Emxl lineage-derived OB interneurons corresponded to GABAergic cells. Indeed, Emx1-derived cells in the $\mathrm{OB}$ glomerular and granule layers coexpressed the neurotransmitter GABA in P0 and adult mice (Fig. $5 A, B$ ), whereas cortical cells derived from this lineage did not (supplemental Fig. 5, available at www.jneurosci.org as supplemental material). Furthermore, Emx1-cre lineage interneurons in the $\mathrm{OB}$ did not express vGlut1/2 (Fig. 5) or TBR1, a transcription factor found in glutamatergic projection neurons in the cortex 
and OB (supplemental Fig. 4, available at www.jneurosci.org as supplemental material). Together, the above data show that the Emx1 lineage contributes to multiple GABAergic OB interneurons, including the calretinin ${ }^{+}$PGCs.

Emx1 lineage-derived cells contribute to adult SVZ neurogenesis

$\mathrm{EGFP}^{+}$cells were found in the adult SVZ of Emx1-cre:ZEG brains in the dorsal, wedge-like area between the striatum and corpus callosum and along the dorsal part of the medial wall of the lateral ventricle (Fig. 6B) (see also Fig. 9C). Many EGFP ${ }^{+}$ cells in the wedge area of neonatal and adult mice coexpressed Ki67, a marker for proliferating cells (Gerdes et al., 1991) (Fig. 6), suggesting that Emx1 lineagederived cells actively proliferate in the adult SVZ. We also found many EGFP ${ }^{+}$ cells in the rostral migratory stream (RMS) and the core of the OB, where many young neurons are tangentially migrating into the $\mathrm{OB}$ (Fig. $4 E^{\prime}$ ). Neuroblasts first migrate tangentially from the SVZ to the OB and then migrate radially into the glomerular or granule cell layers, where they develop dendritic arbors with spines; this process takes $\sim 15 \mathrm{~d}$ (Petreanu and Alvarez-Buylla, 2002). Adult Emx1cre:ZEG mice were injected once with BrdU, and their brains were sectioned and analyzed $15 \mathrm{~d}$ later. A subpopulation of the $\mathrm{BrdU}^{+}$cells in the glomerular and granule cell layers were $\mathrm{EGFP}^{+}$(Fig. 6C,D). These data indicate that Emx1 lineage-derived cells contribute to the SVZ progenitors that continue to generate new granule and periglomerular neurons in the adult OB.

The Dlx5/6i lineage contributes to $\mathrm{TH}$, calbindin, and calretinin interneuron subtypes in the $\mathrm{OB}$

We next studied a transgenic mouse line that expresses Cre recombinase under the control of an intergenic Dlx5/6 enhancer (Dlx5/6i), which is active in progenitors derived from the LGE, MGE, and septum,

but not from pallium (Monory et al., 2006). We crossed Dlx5/6icre mice to Z/EG reporter mice (Dlx5/6i-cre:ZEG) and found strong EGFP expression in OB interneuron layers and subcortical regions, as well as scattered cells in the cortex at both $\mathrm{P} 0$ and adult ages [supplemental Fig. $4 A$ (and data not shown), available at www.jneurosci.org as supplemental material]. Dlx5/6i-lineage cells in the cortex coexpressed GABA (supplemental Fig. 4, available at www.jneurosci.org as supplemental material), as shown previously (Bulfone et al., 1998; Anderson et al., 1999; Toresson and Campbell, 2001; Yun et al., 2003). As anticipated, within the $\mathrm{OB}, \mathrm{Dl} \times 5 / 6 i$-lineage cells coexpressed GABA but did not express vGlut1, vGlut2, or TBR1 (supplemental Figs. 2 D-F, 3A, available at www.jneurosci.org as supplemental material).
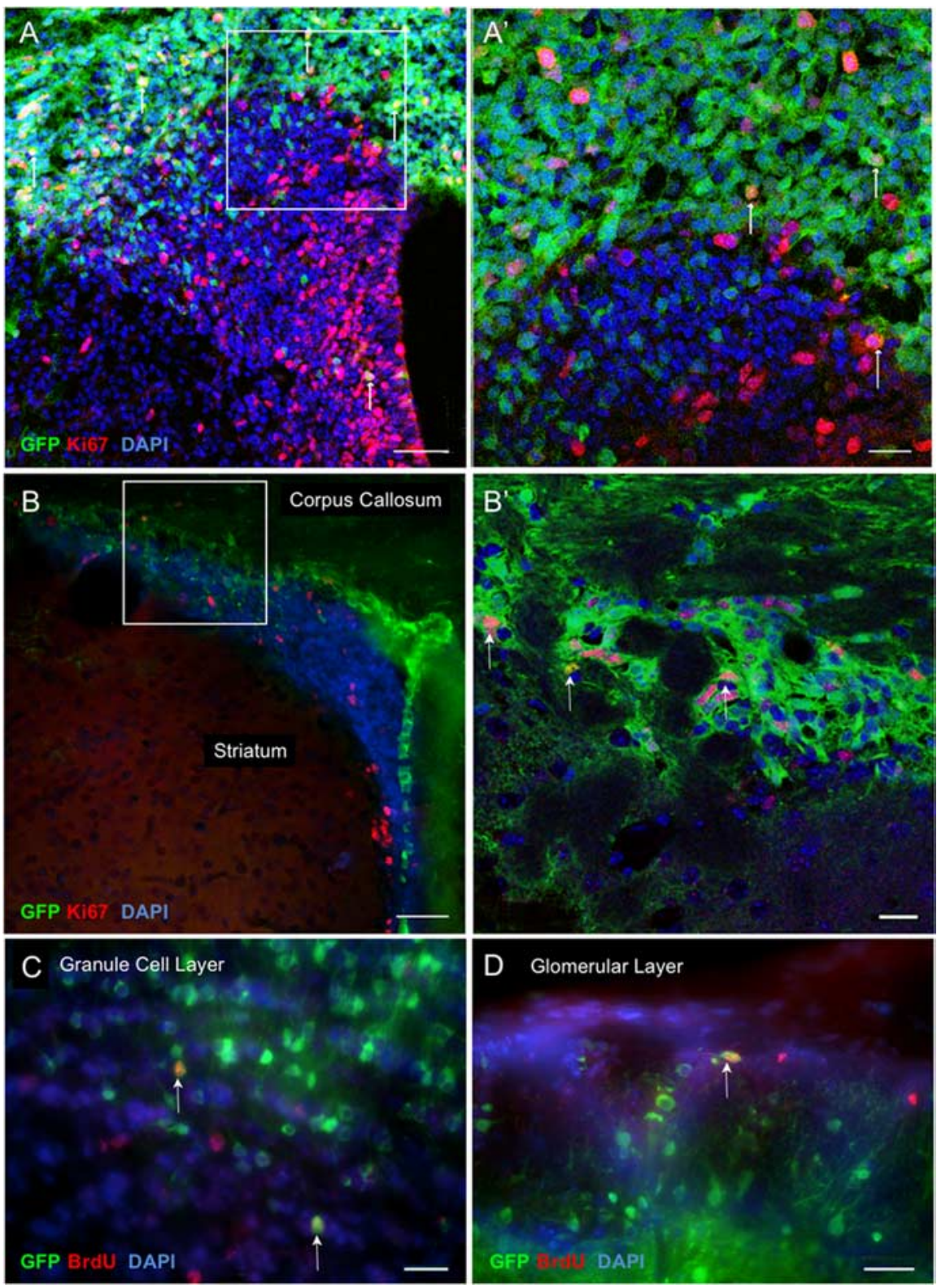

Figure 6. Emx1 lineage cells actively proliferate in postnatal SVZ and participate in adult neurogenesis of OB cells. $A$, Many $\mathrm{EGFP}^{+}$cells in P0 SVZ express Ki67, a proliferation marker. $\boldsymbol{A}^{\prime}$, Higher magnification of $\boldsymbol{A}$. $\boldsymbol{B}$, EGFP ${ }^{+}$cells in adult SVZ continue to dult neurogenesis. $\boldsymbol{D}$, Example of an EGFP ${ }^{+}$periglomerular cell labeled with BrdU. Arrows indicate cells double labeled with Ki67 and $\operatorname{EGFP}(\boldsymbol{A}, \boldsymbol{B})$ or $\operatorname{BrdU}$ and $\operatorname{EGFP}(\boldsymbol{C}, \boldsymbol{D})$. Scale bars: $\boldsymbol{A}, 50 \mu \mathrm{m} ; \boldsymbol{A}^{\prime}, \boldsymbol{B}^{\prime}, 20 \mu \mathrm{m} ; \boldsymbol{B}, 100 \mu \mathrm{m} ; \boldsymbol{C}, \boldsymbol{D}, 30 \mu \mathrm{m}$.

In the $\mathrm{OB}$ glomerular and granule cell layers, Dlx5/6ilineage cells expressed TH, calbindin, and calretinin (Fig. 7). Among the $\mathrm{OB}$ interneuron subtypes, we found that many, but not all, $\mathrm{TH}^{+}(\mathrm{P} 0,39 \pm 0.04 \%$; adult, $54 \pm 4.6 \%)$, calbindin ${ }^{+}$ $(\mathrm{P} 0,51 \pm 0.04 \%$; adult, $22 \pm 2.4 \%)$, and calretinin ${ }^{+}(\mathrm{P} 0,18 \pm$ $0.02 \%$; adult, $54 \pm 3.4 \%$ ) cells were derived from the Dlx5/6i lineage ( $n=3$ mice each) (Fig. $4 J)$. Our quantification data indicate that at $\mathrm{P} 0$, a significant number of $\mathrm{OB}$ interneurons $\left(>50 \%\right.$ of $\mathrm{TH}^{+},>40 \%$ of calretinin ${ }^{+}$, and $40 \%$ of calbindin ${ }^{+}$) were not derived from either the Emx1 or Dlx5/6i lineage. Many of the $\mathrm{OB}$ interneurons at $\mathrm{P} 0$ may be immature and may not express cell-specific markers at the levels required for detection. We also do not know whether the Dlx5/6i labels all cells that express Dlx5 and Dlx6. 


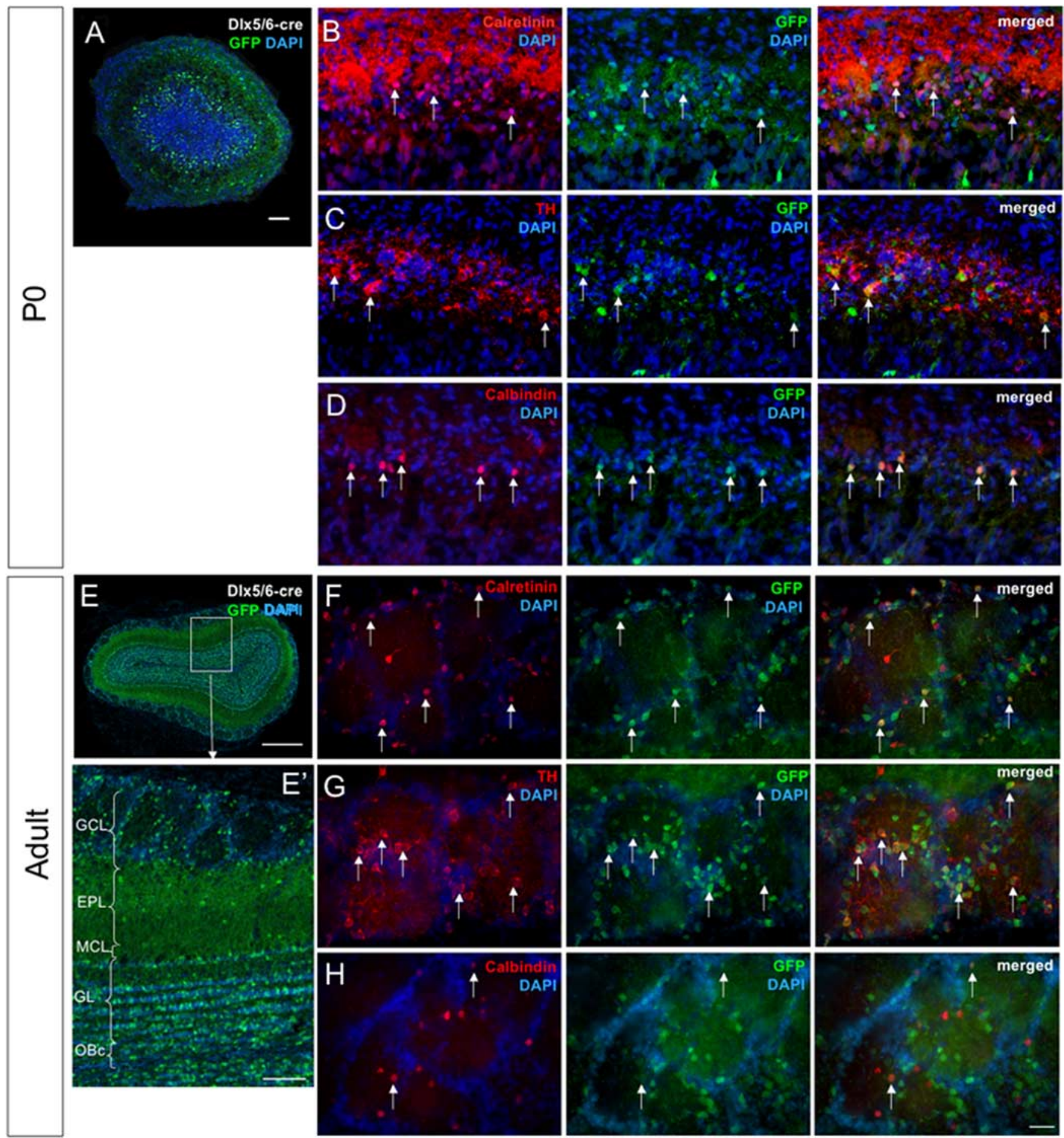

Figure 7. Dlx5/6i-cre lineage gives rise to $\mathrm{TH}^{+} /$calbindin ${ }^{+} /$calretinin ${ }^{+}$OB interneurons. A, EGFP expression in OB from Dlx5/6i lineage at P0. $B-D$, Examples of EGFP ${ }^{+}$cells that coexpress TH, calbindin, or calretinin. $\boldsymbol{E}$, EGFP expression in $0 B$ from Dlx5/6i lineage in adult. $\boldsymbol{E}^{\prime}$, Higher magnification of OB showing that EGFP expression is found in all layers of the $0 \mathrm{~B}$. $\boldsymbol{F}-\boldsymbol{H}$, Examples of EGFP ${ }^{+}$ cells in adult $\mathrm{OB}$ that coexpress $\mathrm{TH}$, calbindin, or calretinin. Arrows point to double-labeled cells. GL, Glomerular layer; $\mathrm{EPL}$, external plexiform layer; $\mathrm{MCL}$, mitral cell layer; $\mathrm{GCL}$, granule cell layer; $\mathrm{OBC}$, olfactory bulb core. Scale bars: $\boldsymbol{A}, \boldsymbol{E}^{\prime}, 100 \mu \mathrm{m} ; \boldsymbol{B}-\boldsymbol{D}, \boldsymbol{F}-\boldsymbol{H}, 30 \mu \mathrm{m} ; \boldsymbol{E}, 0.5 \mathrm{~mm}$

Our results indicate that both the Emx1 and Dlx5/6i lineages contribute to TH, calbindin, and calretinin OB interneuron subtypes at $\mathrm{P} 0$ and in the adult. The presence of calreti$\operatorname{nin}^{+} \mathrm{OB}$ interneurons within the Dlx5/6 lineage was surprising, given that we did not observe calretinin ${ }^{+}$cells when we transplanted LGE progenitors to the adult SVZ (Fig. 3). However, Dlx5 and Dlx6 are also prominently expressed in the embryonic septum, suggesting that septal progenitors may give rise to calretinin ${ }^{+}$cells.
Emx1-cre lineage cells coexpress DLX2 in the pallial-dLGE and pallial-septal border in the rostral embryonic forebrain and adult SVZ

The contributions of the Emx1-cre and Dlx5/6i-cre lineages to both granule and periglomerular interneurons in the $\mathrm{OB}$ and the continued production of these cells during adult neurogenesis (Fig. 5) (Doetsch et al., 2002) prompted us to analyze the regional expression patterns of Emx1 and Dlx2 markers 

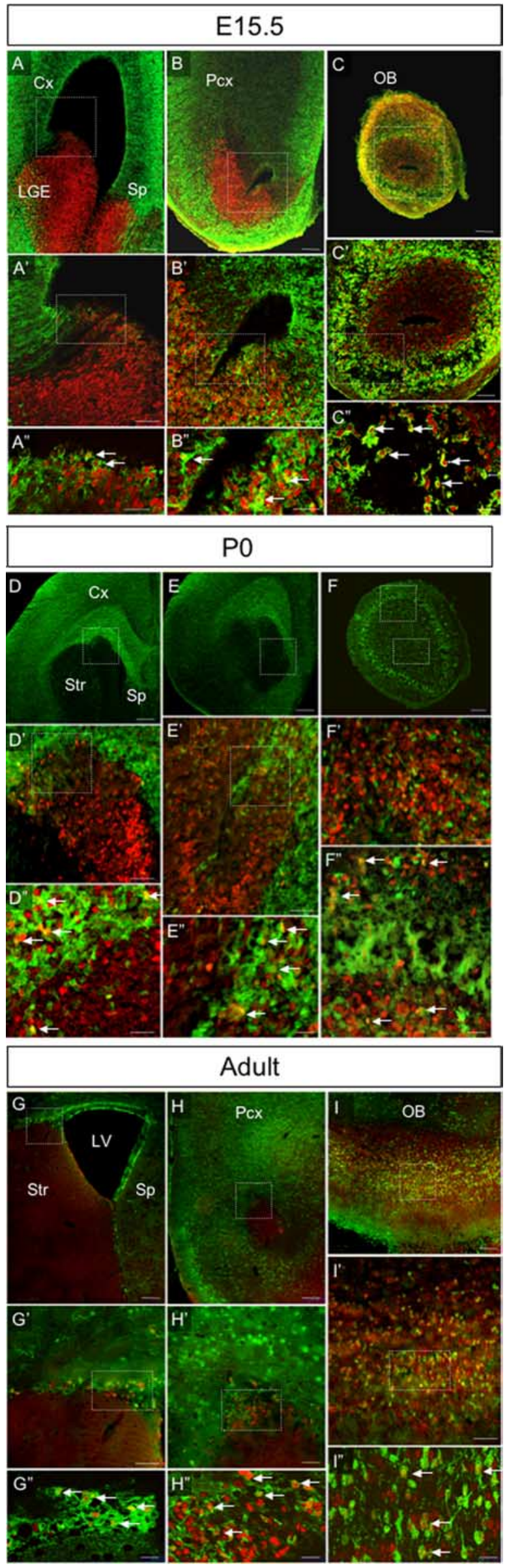

during embryonic and adult neurogenesis. Emxl and Dlx homeobox proteins are classically associated with separate populations of progenitors (Fernandez et al., 1998; Puelles et al., 2000; Zerucha et al., 2000; Chan et al., 2001; Gorski et al., 2002). However, the above results suggest that a subpopulation of $\mathrm{OB}$ interneurons is derived from progenitors expressing both of these transcription factors.

We immunostained E15, P0, and adult Emx1-cre:ZEG mouse brains for EGFP and DLX2 in the regions thought to generate OB progenitors. EGFP was used to detect Emx1 lineage-derived cells, and antibodies were used to detect DLX2, a transcription factor that regulates Dlx5/6 expression and is widely expressed in subpallial progenitors (Zerucha et al., 2000). As observed in previous studies, the majority of $\mathrm{EGFP}^{+}$cells were found dorsally in the pallium, and most of the DLX2 expression in the SVZ was restricted to the subpallium. However, at E15.5 we observed a few EGFP ${ }^{+}$cells that coexpressed DLX2 in the VZ of the ventral pallium/dLGE (Fig. $8 \mathrm{~A}$ ), consistent with observations by Gorski et al. (2002) of a few radially aligned clones in the dLGE. In addition, we also observed Emx1-lineage cells coexpressing DLX2 in the VZ along the pallial/septal boundary (Fig. 9A). Further anteriorly, in the progenitor zone of the developing $\mathrm{OB}$ at E15.5, we found many Emx1 lineage cells that were DLX2 ${ }^{+}$(Fig. 8C). Progressively rostral sections had increasing numbers of double-labeled cells. Within the OB, most Emxl lineage cells in the developing granule and glomerular layers coexpressed DLX2, suggesting that the Emx1 lineage-derived cells in the $\mathrm{OB}$ come from progenitors that express both transcription factors at some point of their development.

Similar areas of overlap between the Emx1-cre lineage and DLX2 expression were also observed at $\mathrm{P} 0$ and in the adult SVZ at the striatal-cortical boundary (Fig. $8 D, G$ ) and at the septal-cortical boundary (Fig. 9B,C). Many Emxl lineage-derived neurons in the OB also coexpressed DLX2 (Figs. 8, 9). Therefore, a subpopulation of $\mathrm{OB}$ GABAergic interneurons is derived from progenitors of both Emxl and Dlx lineages. We do not know whether Emx1-cre-derived cells continue to express Emx1 while expressing DLX2 during neurogenesis or the sequence of expression of these two transcription factors during the differentiation of these progenitor cells.

\section{Pallial and septal progenitors can give rise to calretinin ${ }^{+}$ OB interneurons}

The Emxl lineage gave rise to a significant proportion of $\mathrm{OB}$ interneurons, including many calretinin ${ }^{+}$cells. Given that our dLGE transplants did not generate calretinin ${ }^{+}$cells in the $\mathrm{OB}$ (Fig. 3), we tested whether pallial progenitors can contribute to this population of $\mathrm{OB}$ interneurons. We grafted $\mathrm{EGFP}^{+} \mathrm{E} 16$ pallial progenitors to the adult SVZ, excluding in our dissection the region just dorsal to the lateral sulcus to avoid any contamination from the dLGE. The fate of grafted cells in the OB was studied $40 \mathrm{~d}$ later (Fig. 10A,B).

\footnotetext{
Figure 8. Cells in the Emx1-cre lineage express DLX2 in the VZ/SVZ at the pallial-subpallial boundary and in the RMS and $\mathrm{OB}$ at E15, PO, and in the adult. Emx1-cre lineage is shown in green, and DLX2 is shown in red. $A-C$, Double labeling shows that DLX2 is expressed in the Emx-1 lineage cells at E15.5 in ventral pallium/dorsal LGE (A), RMS (B), and OB (C). D-F, Same double-labeling analysis at PO. G-I, Double-labeling analysis in adult. Notice that adult SVZ has significant overlap of Emx1-cre lineage with DLX2 compared with LGE of E15.5 embryo. $\boldsymbol{A}^{\prime}-\boldsymbol{I}^{\prime}$, Higher magnification of $A-I$. $A^{\prime \prime}-I^{\prime \prime}$, Higher magnification of $\boldsymbol{A}^{\prime}-\boldsymbol{I}^{\prime}$. Arrows point to doublelabeled cells. Cx, Cortex; LV, lateral ventricle; Pcx, prefrontal cortex; Sp, septum; Str, striatum. Scale bars: $A-I, 100 \mu \mathrm{m} ; A^{\prime}-I^{\prime}, 50 \mu \mathrm{m} ; A^{\prime \prime}-I^{\prime \prime}, 20 \mu \mathrm{m}$.
} 

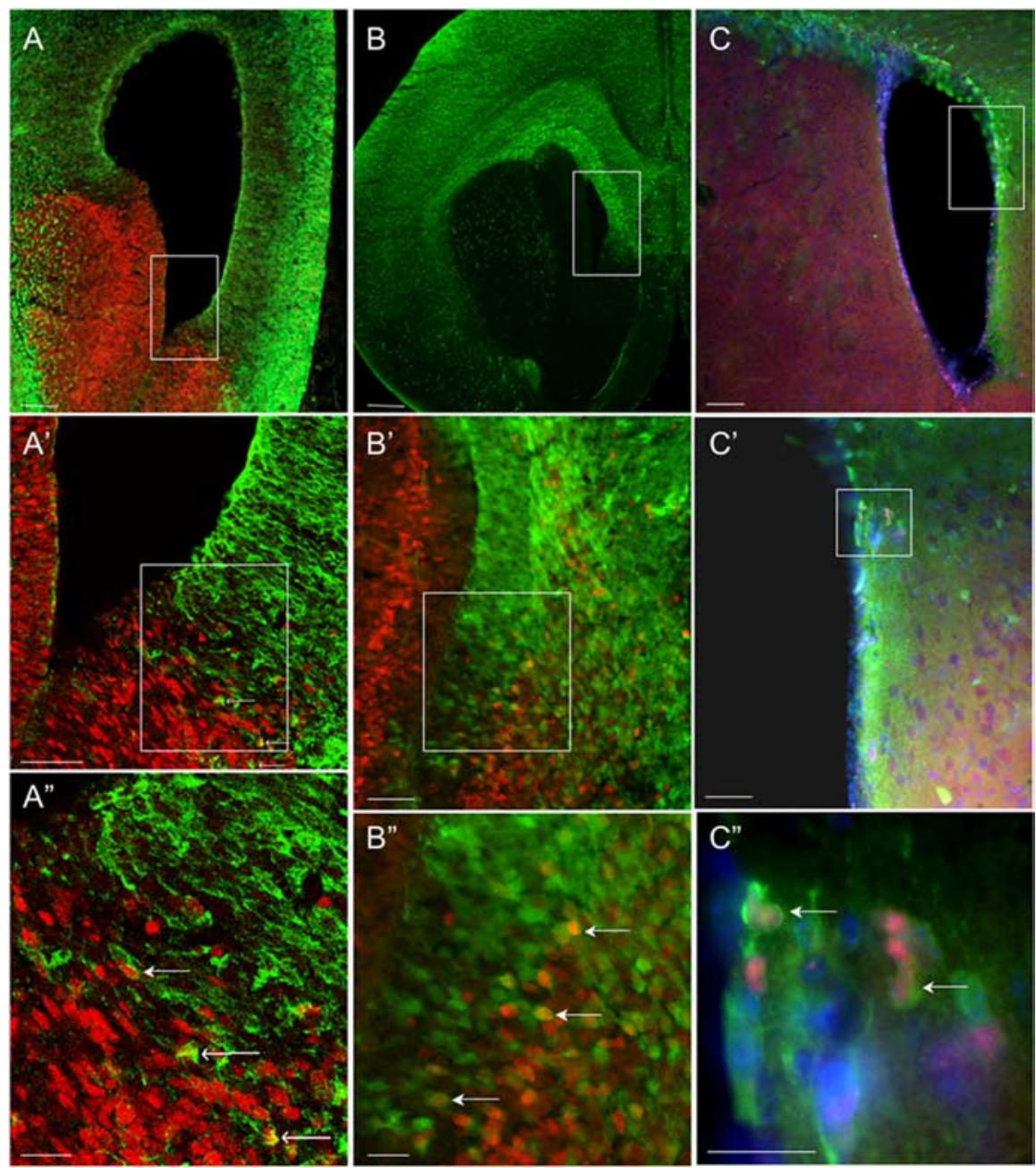

Figure 9. Cells from the Emx1-cre lineage express DLX2 at the rostral pallial-septal boundary. Emx1-cre lineage is shown in green, and DLX2 is shown in red. $\boldsymbol{A}-\boldsymbol{C}, \mathrm{DLX} 2$ expression in the Emx1 lineage cells at the pallial-septal boundary at E15.5 $\left(\boldsymbol{A}-\boldsymbol{A}^{\prime \prime}\right)$, P0 $\left(\boldsymbol{B}-\boldsymbol{B}^{\prime \prime}\right)$, and adult $\left(\boldsymbol{C}-\boldsymbol{C}^{\prime \prime}\right)$. $\boldsymbol{A}^{\prime}-\boldsymbol{C}^{\prime}$, Higher magnification of $\boldsymbol{A}-\boldsymbol{C} . \boldsymbol{A}^{\prime \prime}-\boldsymbol{C}^{\prime \prime}$, Higher magnification of $\boldsymbol{A}^{\prime}-\boldsymbol{C}^{\prime}$. Arrows point to coexpressing cells. Scale bars: $\boldsymbol{A}-\boldsymbol{C}, 100 \mu \mathrm{m} ; \boldsymbol{A}^{\prime}-\boldsymbol{C}^{\prime}, 50 \mu \mathrm{m} ; \boldsymbol{A}^{\prime \prime}-\boldsymbol{C}^{\prime \prime}, 20 \mu \mathrm{m}$.

$\mathrm{EGFP}^{+}$(graft-derived) neurons in the $\mathrm{OB}$ were observed in the granule and glomerular layers of the OB. These cells had the morphology of granule and periglomerular neurons, indicating that pallial progenitors can contribute $\mathrm{OB}$ interneurons. Many of the $\mathrm{EGFP}^{+}$cells in the glomerular layer also expressed calretinin $(67.0 \pm$ $7.0 \% ; 32$ cells counted from $n=2$ mice). In the granule cell layer, $9.0 \pm 7.3 \%$ ( 143 cells counted from $n=2$ mice $)$ of $\mathrm{EGFP}^{+}$granule cells were calretinin ${ }^{+}$(Fig. 10). $\mathrm{EGFP}^{+}$cells with the morphologies of migrating neuroblasts were observed in both the RMS and the core of the OB $40 \mathrm{~d}$ after transplantation (Fig. $10 F^{\prime}, F^{\prime \prime}$ ), suggesting that some of the graft-derived cells continue to produce young neurons in the adult brain. None of the graft-derived cells ( 0 of 97 cells counted) in the OB expressed Reelin (Fig. 10E), and thus they are unlikely to represent ectopic Cajal-Retzius cells.

We next tested whether cells isolated from the septum can generate calretinin ${ }^{+}$interneurons in the OB. The developing septum expresses DLX transcription factors (Anderson et al., 1997a), and the dorsal region of the septum contains some $E m \times 1^{+}$cells (Puelles et al., 2000) (Fig. 9). We transplanted E16 septal progenitors to the adult SVZ (Fig. 11A). Forty days after transplantation, we found graft-derived granule and PGCs in the OB. Calretinin ${ }^{+}$cells constituted $11.8 \pm 3.2 \%$ of graft-derived granule cells (191 cells counted from $n=2$ mice) and $32.1 \pm$
$17.9 \%$ of graft-derived PGCs (13 cells counted from $n=2$ mice) (Fig. 11). Together, these data show that the embryonic pallium and septum, but not the LGE, when grafted into the adult SVZ, have the potential to generate calretinin ${ }^{+}$ cells in the OB.

\section{Discussion}

The above results indicate that the three main subtypes of periglomerular interneurons expressing calretinin, calbindin, and $\mathrm{TH}$ continue to be replaced in the adult brain but mature and are eliminated at different rates. These interneurons are derived from progenitors that express transcription factors classically associated with both pallium and subpallium. Perhaps the most unexpected observation is that embryonic progenitors from different germinal zones appear to differ in their potential to generate OB interneuron subtypes within the adult SVZ.

\section{Diversity of mouse OB interneuron subtypes and turnover}

Similar to what has been described in the rat (Kosaka et al., 1998), the mouse OB contains $\mathrm{TH}^{+}$, calbindin ${ }^{+}$, and calreti$\operatorname{nin}^{+}$cells. These cells coexist as mutually exclusive, nonoverlapping populations around glomeruli. In contrast to the rat, in which only $\mathrm{TH}^{+}$cells were found to be GABAergic (Kosaka and Kosaka, 2005), we found that all three populations of PGCs in the mouse were subtypes of GABAergic neurons. Differences between mouse and rat may be attributable to species differences (Kosaka and Kosaka, 2005) or to the use of Gad67-EGFP (Tamamaki et al., 2003), which may provide a higher sensitivity to detect GABAergic cells than antibody labeling or may label different populations of GABAergic neurons compared with Gad65-GFP mice (Parrish-Aungst et al., 2007).

We used BrdU-labeling to follow the time course of interneuron turnover in the adult $\mathrm{OB}$. The proportion of $\mathrm{BrdU}^{+}$cells that express TH 10 months after BrdU injection dropped dramatically compared with the proportion of $\mathrm{BrdU}^{+}$cells that expressed either calretinin or calbindin. We found that $\mathrm{TH}^{+}$cells were replaced more frequently and had a shorter lifespan than calreti$\operatorname{nin}^{+}$and calbindin ${ }^{+}$PGCs. The higher rate of turnover of $\mathrm{TH}^{+}$ cells compared with calretinin ${ }^{+} /$calbindin $^{+}$cells is interesting in light of the differences in their connections within the OB circuitry. Previous studies indicate that $\mathrm{TH}^{+}$cells (type I PGCs) make synaptic connections in the glomeruli with axons of olfactory receptor neurons. In contrast, calretinin ${ }^{+} /$calbindin $^{+}$cells (type II PGCs) make connections only with mitral and tufted projection neurons (Kosaka et al., 1998). Consistent with these characteristics, we observed that $\mathrm{TH}^{+}$processes intermix in the glomeruli with vGlut ${ }^{+}$processes, presumably those of olfactory receptor neurons, whereas calbin $\operatorname{din}^{+} /$calretinin $^{+}$processes 
avoid them. Thus, our data suggest that the type $\mathrm{I} \mathrm{TH}^{+}$cells have a higher turnover rate than type II calbindin ${ }^{+} /$calreti- $^{-}$ $\operatorname{nin}^{+}$cells. Interestingly, however, the relative ratio of the different subtypes of $\mathrm{OB}$ periglomerular interneurons remained relatively constant from birth to adulthood, despite continuous production of these cells. The mechanisms by which these ratios are maintained remain unknown.

\section{Embryonic progenitors outside of the} LGE can produce $\mathrm{OB}$ interneurons Several reports have suggested that the LGE is the embryonic progenitor zone that generates OB interneurons and develops into the adult SVZ (Wichterle et al., 1999; Stenman et al., 2003; Waclaw et al., 2006). Furthermore, the LGE has been subdivided into dorsal (dLGE) and ventral (vLGE) parts; dLGE gives rise to OB interneurons, whereas the ventral region gives rise to striatal cells (Stenman et al., 2003; Waclaw et al., 2006). These observations are consistent with previous reports indicating that mutations in transcription factors expressed in the embryonic dLGE $\left(D l \times 1 / 2^{-/-}\right.$and $\left.G s h 1 / 2^{-/-}\right)$eliminate GABAergic cells from the prenatal OB (Bulfone et al., 1998; Toresson and Campbell, 2001; Yun et al., 2003). There also has been a correlation between the expression of transcription factors Er81 and Sp8 in LGE and certain subpopulations of OB interneurons (Stenman et al., 2003; Waclaw et al., 2006). However, expression of these transcription factors is not restricted to the dLGE (Waclaw et al., 2006; Long et al., 2007); therefore, previous studies cannot establish that the dLGE is the only source of OB interneurons.

We provide evidence that E14-E16 LGE progenitors grafted into the adult brain do not contribute to calretinin ${ }^{+} \mathrm{OB}$ interneurons, whereas similar grafts of pallial and septal progenitors did produce this subtype of interneuron. These results suggest that calretinin ${ }^{+} \mathrm{OB}$ interneurons come from regions outside the LGE, perhaps from pallium, septum, or both. Because our heterochronic transplants reveal only the potential of the grafted progenitors within the novel environment of the postnatal SVZ, it is important to note that progenitors from the LGE, pallium, and septum may behave differently within the embryonic environment.

A recent study by De Marchis et al. (2007) used similar heterochronic grafting of embryonic LGE into the adult SVZ. Consistently with what we observed, De Marchis et al. (2007) found that the embryonic LGE grafted postnatally produced virtually no calretinin ${ }^{+} \mathrm{OB}$ interneurons. They found that neonatal SVZ dissections generated calretinin ${ }^{+} \mathrm{OB}$ interneurons when grafted to the adult SVZ environment. They suggest that the production of calretinin $^{+}$cells, therefore, occurs at later stages of development. However, as shown above, many calretinin ${ }^{+} \mathrm{OB}$ interneu- rons are already present in the $\mathrm{OB}$ by birth, and our results suggest that embryonic pallial and septal progenitors have the potential of generating $\mathrm{OB}$ calretinin ${ }^{+}$cells, unlike LGE progenitors. Furthermore, experiments that selectively label primary progenitors in the rostral septum and cortical ventricular roof (anatomically homologous to embryonic pallium) of $\mathrm{P} 0$ animals show that these regions give rise to calretinin ${ }^{+}$cells in the $\mathrm{OB}(\mathrm{F}$. Merkle, Z. Mirzadeh, A. Alvarez-Buylla, unpublished observations). Therefore, calretinin ${ }^{+} \mathrm{OB}$ interneuron specification may involve spatial identity of the progenitors and not solely depend on developmental stages. Additional experiments, such as homotopic/homochronic grafting, should provide valuable insight into the contribution of embryonic LGE, pallium, and septum to the postnatal SVZ.

Our transplant results do not conflict with recent evidence showing that Sp8 is required for production of one-half of the calretinin $^{+} \mathrm{OB}$ interneurons (Waclaw et al., 2006), because Sp $8^{+}$ is expressed in the septum and pallium, in addition to the dLGE (Waclaw et al., 2006; Long et al., 2007). The septal and pallial 
A
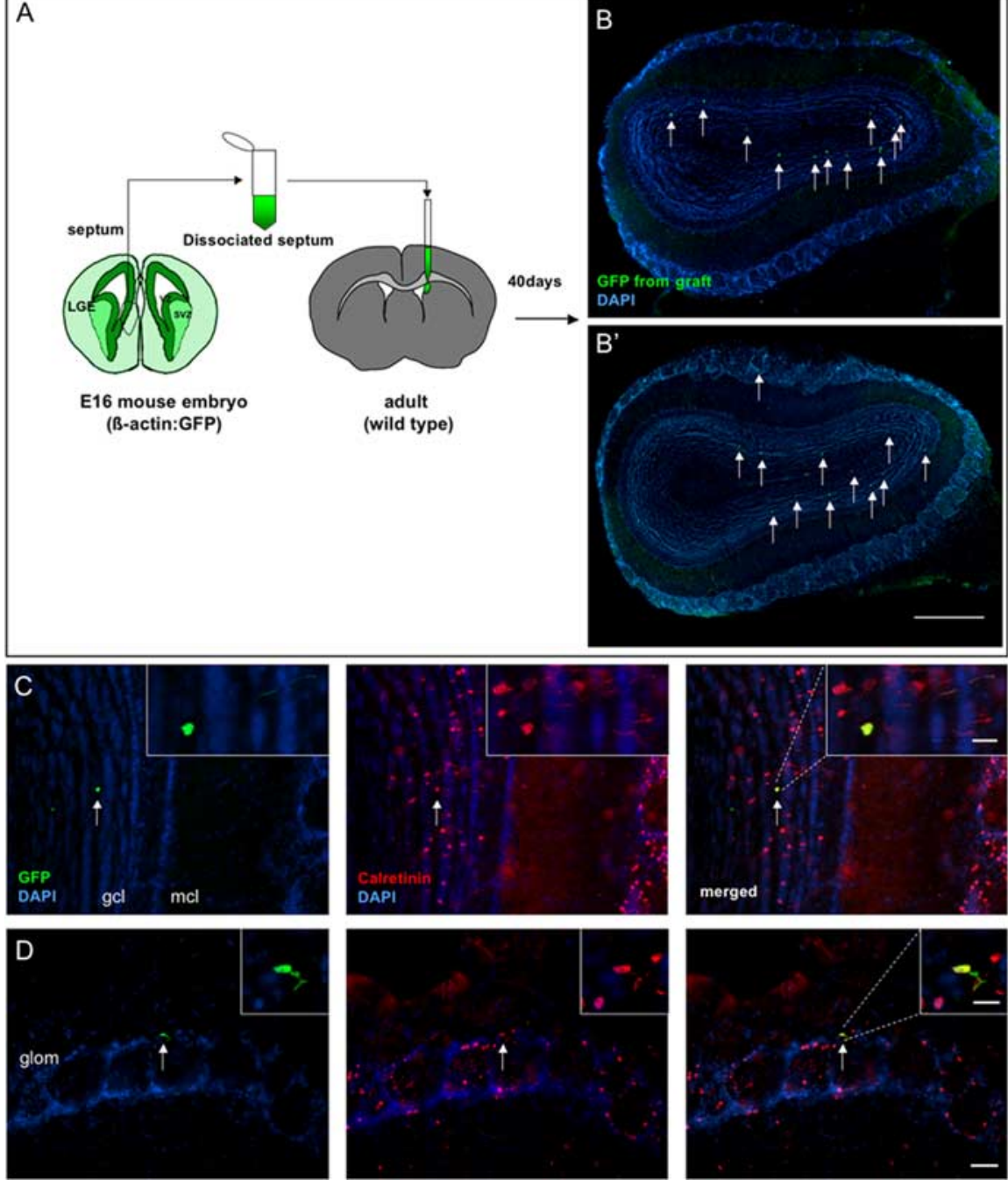

Figure 11. Septal progenitors give rise to calretinin ${ }^{+} O B$ neurons. $A$, Schematic of region dissected for grafting. $B, B^{\prime}$, Two examples of $\mathrm{OB}$ section showing that graft-derived cells migrate to interneuron layers. $\boldsymbol{C}, \boldsymbol{D}$, Examples of $\mathrm{EGFP}^{+}$septal graftderived cells that express calretinin in granule cell layer $(\boldsymbol{C}$ ) or glomerular layer $(\boldsymbol{D})$. Insets, Higher magnification of cell. gcl, Granule cell layer; $\mathrm{mcl}$, mitral cell layer; glom, glomerular layer. Scale bars: $\boldsymbol{B}, \boldsymbol{B}^{\prime}, 0.5 \mathrm{~mm} ; \boldsymbol{C}, \boldsymbol{D}, 50 \mu \mathrm{m} ; \boldsymbol{C}, \boldsymbol{D}$, Insets, $20 \mu \mathrm{m}$.

in fact, recent work suggests that Emx1cre-expressing cells migrate from pallium into subpallium, where these cells express DLX2 (Willaime-Morawek et al., 2006). Conversely, subpallial-derived DLX $2^{+}$ cells could activate Emx1 during differentiation. Still another possible source of $\mathrm{DLX}_{2}{ }^{+} / E m x 1$ lineage-derived $\mathrm{OB}$ interneurons is a region containing $E m \times 1^{+}$ cells that extends from the confluence of the septum and LGE into the RMS and OB (supplemental Fig. 5G, available at www. jneurosci.org as supplemental material) [for evidence that this region is related to the generation of $\mathrm{OB}$ interneurons, see Long et al. (2007)]. In this region, a subset of Emx1-expressing cells appears to depend on Dlx1/2 function, whereas others do not (supplemental Fig. 5, available at www.jneurosci.org as supplemental material). Consequently, some $\mathrm{OB}$ interneurons may continue to be produced by Dlx1/2-independent $\mathrm{Emx}^{+}$cells. Ultimately, the identification of the precise origin of Emx1-lineage cells in the OB awaits additional experimentation. Our fatemapping results alone do not indicate which particular progenitor domain (LGE, pallium, septum, or boundary regions between these domains) gives rise to neurons in the $\mathrm{OB}$, because we cannot determine the precise relationship between the spatial origin of a cell and its temporal expression of Emx1. However, our data indicate that multiple transcriptional lineages contribute to $\mathrm{OB}$ interneuron diversity, and such transcriptional lineages may be derived from progenitors with distinct potentials to generate specific $\mathrm{OB}$ interneuron subtypes.

\section{Cell-fate diversity in the Emx1 lineage}

contributions to GABAergic OB interneurons, including calretinin cells, are also consistent with fate mapping of the Dlx5/6i and $E m \times 1$ lineages, because these transcription factors are expressed in the septum and pallium, respectively, as well as the dLGE. Furthermore, there is evidence that the embryonic septal region is a source of $\mathrm{Dlx} 5^{+} / \mathrm{Gad} 67^{+}$cells for the OB (Long et al., 2003, 2007).

In the developing and adult $\mathrm{OB}$, the majority of Emx1 lineagederived OB interneurons expressed DLX2. This observation suggests that regardless of their initial origin or lineage, GABAergic OB interneurons eventually express DLX2 as part of their developmental program. This is consistent with previous reports that loss of $D l \times 1 / 2$ function results in the loss of Gad67 expression in the OB (Bulfone et al., 1998; Long et al., 2007). We do not know the precise regions that generate the Emx1 lineage-derived DLX2 ${ }^{+}$cells. In P0 mice, we observed clusters of cells from the Emx1 lineage that coexpress DLX2 in the VZ at the pallial-dLGE border and pallial-septal border. These cells could, through transient amplifying cells, generate a large number of neuroblasts destined for the OB. Another possibility is that pallial-derived Emx1 cells may activate Dlx2 expression during differentiation;
Consistent with previous reports, we find that Emx1-derived cells do not contribute to GABAergic cells in the cortex (Gorski et al., 2002), whereas in the $O B$, cells derived from this lineage express GABA (Fig. 5). OB interneurons from the $E m \times 1$ lineage are localized to the glomerular and superficial granule layers. Interneurons in the superficial granule layer make synaptic contacts predominantly with tufted cells, in contrast to the deeply localized granule cells, which make contact preferentially with mitral cells. Mitral and tufted cells in turn project to different areas of the cortex (Orona et al., 1983). Therefore, the superficial granule cells that are derived from the $E m x 1$ lineage participate in a separate but parallel circuit compared with deep granule cells. Previously, we have shown that the transcription factor Pax6, which is expressed in ventral pallial and dLGE progenitors and in postmitotic neurons, is required for the production of superficial granule cells (Kohwi et al., 2005). In light of our present results, it is possible that superficial granule cell production, and thus the circuit in which they participate, has a distinct cellular and molecular program from deep granule cells.

Our data reveal an unanticipated origin for some interneurons in the $\mathrm{OB}$ and more specifically the calretinin ${ }^{+}$population. 
Grafting and lineage analyses implicate regions with pallial and/or septal characteristics outside the LGE as the site of origin of calretinin ${ }^{+} \mathrm{OB}$ interneurons. The precise territories that produce these cells remain to be determined. Regardless of the exact location and possibly additional progenitor zone(s) that produce OB interneurons, our study presents evidence for multiple progenitor pools contributing to $\mathrm{OB}$ interneuron production. This concept is further supported by recent evidence for progenitors within the embryonic OB generating OB interneurons that differ from those produced in the LGE (Vergano-Vera et al., 2006). Our results raise important questions as to how topographically distinct germinal regions in the embryo develop into the adult neurogenic niche and how the continuous production of OB interneurons from a diverse set of progenitor cells is regulated throughout life.

Note added in proof. While this work was under review, a study by Ventura and Goldman (2007) was published showing that dorsal radial glia give rise to OB interneurons. This work is consistent with the pallial progenitor grafting and Emxl lineagetracing work presented here.

\section{References}

Aimone JB, Wiles J, Gage FH (2006) Potential role for adult neurogenesis in the encoding of time in new memories. Nat Neurosci 9:723-727.

Alvarez-Buylla A, Garcia-Verdugo JM (2002) Neurogenesis in adult subventricular zone. J Neurosci 22:629-634.

Anderson S, Mione M, Yun K, Rubenstein JL (1999) Differential origins of neocortical projection and local circuit neurons: role of Dlx genes in neocortical interneuronogenesis. Cereb Cortex 9:646-654.

Anderson SA, Qiu M, Bulfone A, Eisenstat DD, Meneses J, Pedersen R, Rubenstein JL (1997a) Mutations of the homeobox genes Dlx-1 and Dlx-2 disrupt the striatal subventricular zone and differentiation of late born striatal neurons. Neuron 19:27-37.

Anderson SA, Eisenstat DD, Shi L, Rubenstein JL (1997b) Interneuron migration from basal forebrain to neocortex: dependence on Dlx genes. Science 278:474-476.

Bulfone A, Wang F, Hevner R, Anderson S, Cutforth T, Chen S, Meneses J, Pedersen R, Axel R, Rubenstein JL (1998) An olfactory sensory map develops in the absence of normal projection neurons or GABAergic interneurons. Neuron 21:1273-1282.

Chan CH, Godinho LN, Thomaidou D, Tan SS, Gulisano M, Parnavelas JG (2001) Emxl is a marker for pyramidal neurons of the cerebral cortex. Cereb Cortex 11:1191-1198.

Corbin JG, Gaiano N, Machold RP, Langston A, Fishell G (2000) The Gsh2 homeodomain gene controls multiple aspects of telencephalic development. Development 127:5007-5020.

De Marchis S, Bovetti S, Carletti B, Hsieh YC, Garzotto D, Peretto P, Fasolo A, Puche AC, Rossi F (2007) Generation of distinct types of periglomerular olfactory bulb interneurons during development and in adult mice: implication for intrinsic properties of the subventricular zone progenitor population. J Neurosci 27:657-664.

Doetsch F, Petreanu L, Caille I, Garcia-Verdugo JM, Alvarez-Buylla A (2002) EGF converts transit-amplifying neurogenic precursors in the adult brain into multipotent stem cells. Neuron 36:1021-1034.

Fernandez AS, Pieau C, Reperant J, Boncinelli E, Wassef M (1998) Expression of the Emx-1 and Dlx-1 homeobox genes define three molecularly distinct domains in the telencephalon of mouse, chick, turtle and frog embryos: implications for the evolution of telencephalic subdivisions in amniotes. Development 125:2099-2111.

Gerdes J, Li L, Schlueter C, Duchrow M, Wohlenberg C, Gerlach C, Stahmer I, Kloth S, Brandt E, Flad HD (1991) Immunobiochemical and molecular biologic characterization of the cell proliferation-associated nuclear antigen that is defined by monoclonal antibody Ki-67. Am J Pathol 138:867-873.

Gorski JA, Talley T, Qiu M, Puelles L, Rubenstein JL, Jones KR (2002) Cortical excitatory neurons and glia, but not GABAergic neurons, are produced in the Emx1-expressing lineage. J Neurosci 22:6309-6314.

Hack MA, Saghatelyan A, de Chevigny A, Pfeifer A, Ashery-Padan R, Lledo
PM, Gotz M (2005) Neuronal fate determinants of adult olfactory bulb neurogenesis. Nat Neurosci 8:865-872.

Hadjantonakis AK, Gertsenstein M, Ikawa M, Okabe M, Nagy A (1998) Non-invasive sexing of preimplantation stage mammalian embryos. Nat Genet 19:220-222.

Hinds JW (1968) Autoradiographic study of histogenesis in the mouse olfactory bulb. I. Time of origin of neurons and neuroglia. J Comp Neurol 134:287-304.

Kempermann G, Wiskott L, Gage FH (2004) Functional significance of adult neurogenesis. Curr Opin Neurobiol 14:186-191.

Kohwi M, Osumi N, Rubenstein JL, Alvarez-Buylla A (2005) Pax6 is required for making specific subpopulations of granule and periglomerular neurons in the olfactory bulb. J Neurosci 25:6997-7003.

Kohwi M, Galvão RP, Alvarez-Buylla A (2006) Birth, migration and function of SVZ-derived neurons in the adult brain. In: Mammalian subventricular zones, Chap 3 (Levison SW, ed), pp 84-116. New York: Springer Science, Business Media.

Kosaka K, Kosaka T (2005) Synaptic organization of the glomerulus in the main olfactory bulb: compartments of the glomerulus and heterogeneity of the periglomerular cells. Anat Sci Int 80:80-90.

Kosaka K, Toida K, Aika Y, Kosaka T (1998) How simple is the organization of the olfactory glomerulus? The heterogeneity of so-called periglomerular cells. Neurosci Res 30:101-110.

Long JE, Garel S, Depew MJ, Tobet S, Rubenstein JL (2003) DLX5 regulates development of peripheral and central components of the olfactory system. J Neurosci 23:568-578.

Long JE, Garel S, Alvarez-Dolado M, Yoshikawa K, Osumi N, Alvarez-Buylla A, Rubenstein JL (2007) Dlx-dependent and -independent regulation of olfactory bulb interneuron differentiation. J Neurosci 27:3230-3243.

Lopez-Bendito G, Sturgess K, Erdelyi F, Szabo G, Molnar Z, Paulsen O (2004) Preferential origin and layer destination of GAD65-GFP cortical interneurons. Cereb Cortex 14:1122-1133.

Marin O, Rubenstein JL (2001) A long, remarkable journey: tangential migration in the telencephalon. Nat Rev Neurosci 2:780-790.

Monory K, Massa F, Egertova M, Eder M, Blaudzun H, Westenbroek R, Kelsch W, Jacob W, Marsch R, Ekker M, Long J, Rubenstein JL, Goebbels S, Nave KA, During M, Klugmann M, Wolfel B, Dodt HU, Zieglgansberger W, Wotjak CT, et al. (2006) The endocannabinoid system controls key epileptogenic circuits in the hippocampus. Neuron 51:455-466.

Novak A, Guo C, Yang W, Nagy A, Lobe CG (2000) Z/EG, a double reporter mouse line that expresses enhanced green fluorescent protein upon Cremediated excision. Genesis 28:147-155.

Okabe M, Ikawa M, Kominami K, Nakanishi T, Nishimune Y (1997) 'Green mice' as a source of ubiquitous green cells. FEBS Lett 407:313-319.

Orona E, Scott JW, Rainer EC (1983) Different granule cell populations innervate superficial and deep regions of the external plexiform layer in rat olfactory bulb. J Comp Neurol 217:227-237.

Palmer TD, Markakis EA, Willhoite AR, Safar F, Gage FH (1999) Fibroblast growth factor- 2 activates a latent neurogenic program in neural stem cells from diverse regions of the adult CNS. J Neurosci 19:8487-8497.

Parrish-Aungst S, Shipley MT, Erdelyi F, Szabo G, Puche AC (2007) Quantitative analysis of neuronal diversity in the mouse olfactory bulb. J Comp Neurol 501:825-836.

Petreanu L, Alvarez-Buylla A (2002) Maturation and death of adult-born olfactory bulb granule neurons: role of olfaction. J Neurosci 22:6106-6113.

Puelles L, Kuwana E, Puelles E, Bulfone A, Shimamura K, Keleher J, Smiga S, Rubenstein JL (2000) Pallial and subpallial derivatives in the embryonic chick and mouse telencephalon, traced by the expression of the genes Dlx-2, Emx-1, Nkx-2.1, Pax-6, and Tbr-1. J Comp Neurol 424:409-438.

Shepherd GM (1972) Synaptic organization of the mammalian olfactory bulb. Physiol Rev 52:864-917.

Stenman J, Toresson H, Campbell K (2003) Identification of two distinct progenitor populations in the lateral ganglionic eminence: implications for striatal and olfactory bulb neurogenesis. J Neurosci 23:167-174.

Tamamaki N, Yanagawa Y, Tomioka R, Miyazaki J, Obata K, Kaneko T (2003) Green fluorescent protein expression and colocalization with calretinin, parvalbumin, and somatostatin in the GAD67-GFP knock-in mouse. J Comp Neurol 467:60-79.

Temple S (2001) The development of neural stem cells. Nature 414:112-117.

Toresson H, Campbell K (2001) A role for Gsh1 in the developing striatum and olfactory bulb of Gsh2 mutant mice. Development 128:4769-4780. 
Toresson H, Potter SS, Campbell K (2000) Genetic control of dorsal-ventral identity in the telencephalon: opposing roles for Pax6 and Gsh2. Development 127:4361-4371.

Tucker ES, Polleux F, Lamantia AS (2006) Position and time specify the migration of a pioneering population of olfactory bulb interneurons. Dev Biol 297:387-401.

Ventura RE, Goldman JE (2007) Dorsal radial glia generate olfactory bulb interneurons in the postnatal murine brain. J Neurosci 27:4297-4302.

Vergano-Vera E, Yusta-Boyo MJ, de Castro F, Bernad A, de Pablo F, VicarioAbejon C (2006) Generation of GABAergic and dopaminergic interneurons from endogenous embryonic olfactory bulb precursor cells. Development 133:4367-4379.

Waclaw RR, Allen II ZJ, Bell SM, Erdelyi F, Szabo G, Potter SS, Campbell K (2006) The zinc finger transcription factor Sp8 regulates the generation and diversity of olfactory bulb interneurons. Neuron 49:503-516.

Wichterle H, Garcia-Verdugo JM, Herrera DG, Alvarez-Buylla A (1999) Young neurons from medial ganglionic eminence disperse in adult and embryonic brain. Nat Neurosci 2:461-466.

Wichterle H, Turnbull DH, Nery S, Fishell G, Alvarez-Buylla A (2001) In utero fate mapping reveals distinct migratory pathways and fates of neurons born in the mammalian basal forebrain. Development 128:3759-3771.

Willaime-Morawek S, Seaberg RM, Batista C, Labbe E, Attisano L, Gorski JA, Jones KR, Kam A, Morshead CM, van der Kooy D (2006) Embryonic cortical neural stem cells migrate ventrally and persist as postnatal striatal stem cells. J Cell Biol 175:159-168.

Xu Q, Cobos I, De La Cruz E, Rubenstein JL, Anderson SA (2004) Origins of cortical interneuron subtypes. J Neurosci 24:2612-2622.

Yun K, Potter S, Rubenstein JL (2001) Gsh2 and Pax6 play complementary roles in dorsoventral patterning of the mammalian telencephalon. Development 128:193-205.

Yun K, Garel S, Fischman S, Rubenstein JL (2003) Patterning of the lateral ganglionic eminence by the Gsh1 and Gsh2 homeobox genes regulates striatal and olfactory bulb histogenesis and the growth of axons through the basal ganglia. J Comp Neurol 461:151-165.

Zerucha T, Stuhmer T, Hatch G, Park BK, Long Q, Yu G, Gambarotta A, Schultz JR, Rubenstein JL, Ekker M (2000) A highly conserved enhancer in the Dlx5/Dlx6 intergenic region is the site of cross-regulatory interactions between Dlx genes in the embryonic forebrain. J Neurosci 20:709-721. 